\title{
Immune Checkpoint Modulators: An Emerging Antiglioma Armamentarium
}

\author{
Eileen S. Kim, ${ }^{1}$ Jennifer E. Kim, ${ }^{1}$ Mira A. Patel, ${ }^{1}$ Antonella Mangraviti, \\ Jacob Ruzevick, ${ }^{1}$ and Michael Lim ${ }^{1,2}$ \\ ${ }^{1}$ Department of Neurosurgery, Johns Hopkins University School of Medicine, Baltimore, MD 21205, USA \\ ${ }^{2}$ Department of Oncology, Johns Hopkins University School of Medicine, Baltimore, MD 21205, USA \\ Correspondence should be addressed to Michael Lim; mlim3@jhmi.edu
}

Received 15 September 2015; Revised 1 December 2015; Accepted 3 December 2015

Academic Editor: Daniel Olive

Copyright (C) 2016 Eileen S. Kim et al. This is an open access article distributed under the Creative Commons Attribution License, which permits unrestricted use, distribution, and reproduction in any medium, provided the original work is properly cited.

\begin{abstract}
Immune checkpoints have come to the forefront of cancer therapies as a powerful and promising strategy to stimulate antitumor $\mathrm{T}$ cell activity. Results from recent preclinical and clinical studies demonstrate how checkpoint inhibition can be utilized to prevent tumor immune evasion and both local and systemic immune suppression. This review encompasses the key immune checkpoints that have been found to play a role in tumorigenesis and, more specifically, gliomagenesis. The review will provide an overview of the existing preclinical and clinical data, antitumor efficacy, and clinical applications for each checkpoint with respect to GBM, as well as a summary of combination therapies with chemotherapy and radiation.
\end{abstract}

\section{Introduction}

Over the past five years, a series of landmark publications heralded the advances of checkpoint inhibitors as cancer immunotherapy [1-3]. Recent clinical trials have demonstrated significant response rates with anti-CTLA- 4 and antiPD-1 antibodies in patients with late stage melanoma and squamous cell lung cancer [1,4]. These results, along with the recent FDA approval of ipilimumab (anti-CTLA-4) and nivolumab (anti-PD-1), continue to highlight checkpoint inhibitors' potential as powerful new additions to the modern anticancer armamentarium.

Preclinical and clinical studies have shown that immunotherapy can improve survival and generate a robust antitumor immune response to improve cancer therapy $[5,6]$. Under normal physiologic conditions, immune homeostasis is regulated by a careful balance of activating and inhibitory signals. These "immune checkpoints" (Figure 1) play a critical role in regulating the cells of the immune system. Dysregulation of these checkpoints has been implicated in the pathologically up- or downregulated immune responses seen in chronic infection, autoimmunity, and cancer.

Tumor cells have developed several strategies to exploit these checkpoints and circumvent the host immune defenses.
Glioblastoma multiforme (GBM) is the most common central nervous system (CNS) tumor, which has been shown to evade host antitumor response by decreasing immune activation and antigen recognition through several mechanisms. These methods include inducing $\mathrm{T}$ cell anergy and lymphopenia, decreasing synthesis of antibodies, increasing immunosuppressive cytokines (i.e., IL10 and TGF- $\beta$ ), upregulating inhibitory molecules of T cells (i.e., Fas ligand [FasL] and programmed death ligand-1 [PDL-1]), and recruiting regulatory $\mathrm{T}$ cells (Tregs) and myeloid derived suppressor cells (MDSCs) to subdue immune response [7-13].

The recent discovery of lymphatic vessels in the brain has generated much excitement towards an immune approach to treatment of brain malignancies [14]. This finding provides anatomic evidence for immune communications between the periphery and CNS and may support the long-standing theory that activated, circulating $\mathrm{T}$ cells can cross the blood brain barrier after peripheral vaccination or checkpoint inhibition. At present, several studies have demonstrated a positive correlation between high lymphocytic infiltration of primary brain tumors and overall survival [15-21]. Targeted immunotherapy has, therefore, emerged as a promising new approach for treatment, based on the principle that augmenting tumor infiltrating lymphocytes (TILs) activity 


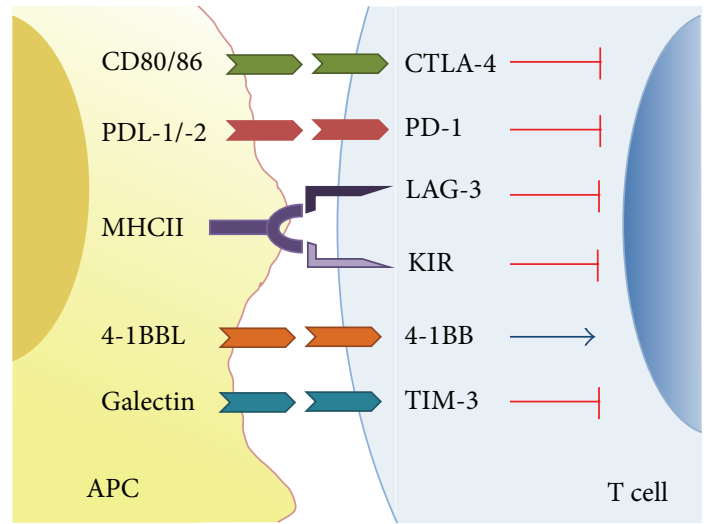

FIGURE 1: Negative and positive immune checkpoint receptors and ligands.

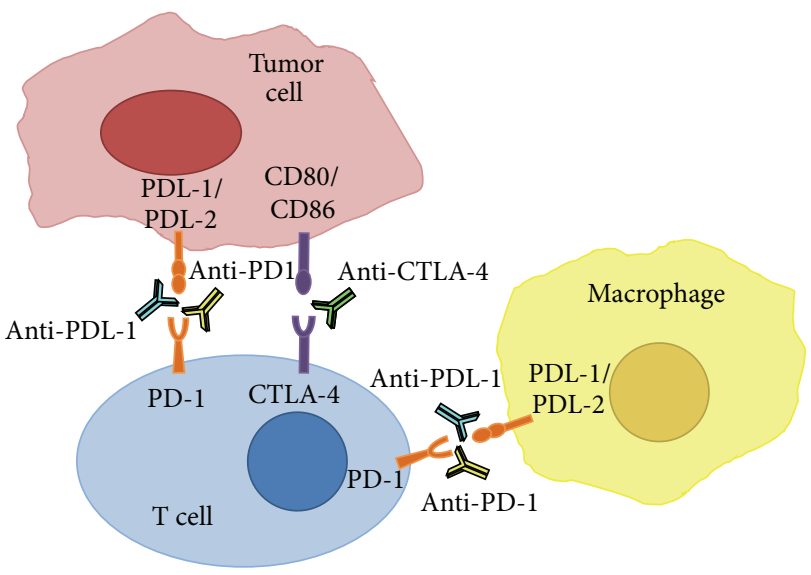

FIGURE 2: Anti-checkpoint antibodies and their targets.

in the tumor microenvironment could translate to tumor regression [22, 23]. Monoclonal antibodies as agonists or antagonists that target checkpoint inhibitors have emerged as potential strategies to restrict TIL inhibiting signals from the tumor and circulating monocytes, block negative signals and cytokines that inhibit $\mathrm{T}$ cell activity, and stimulate systemic immunity (Figure 2) [24].

In this review, we will discuss a series of immune checkpoints that have emerged as potential targets for therapeutic blockade, with an emphasis on those pertinent to the treatment of malignant gliomas. This discussion will touch upon cellular mechanisms, clinical relevance, and outcomes of both preclinical and clinical studies pertaining to each checkpoint. We will also address the topics of combination therapy with other checkpoints molecules as well as other modalities.

\section{Immune Checkpoints}

2.1. CTLA-4. Cytotoxic T lymphocyte antigen-4 (CTLA-4) is widely regarded as the archetypal $\mathrm{T}$ cell intrinsic inhibitory checkpoint. A member of the immune regulatory CD28-B7 immunoglobulin superfamily [25], CTLA-4, acts largely on

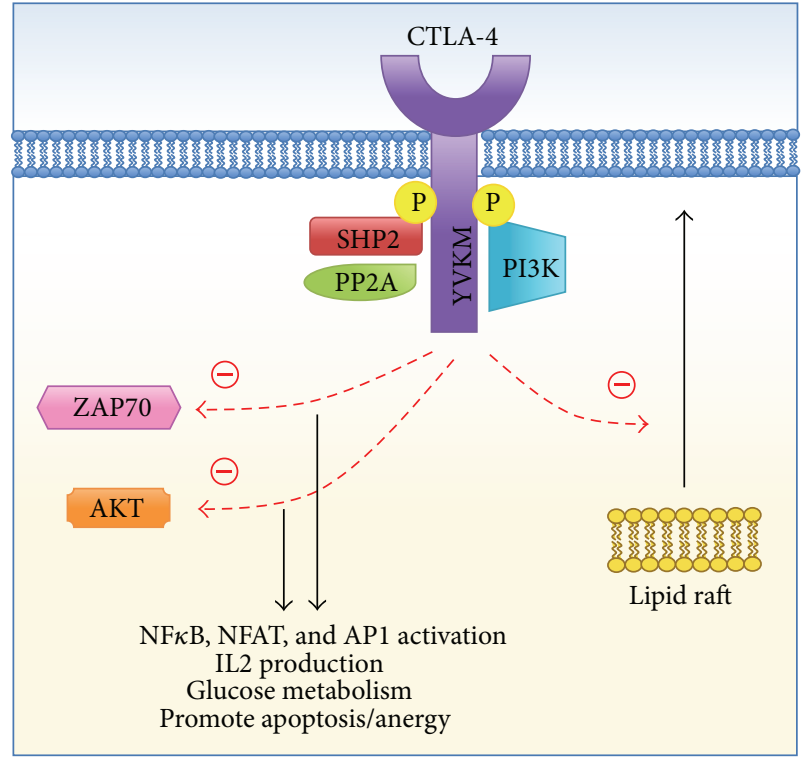

FIGURE 3: CTLA-4 signaling cascade.

naïve and resting $\mathrm{T}$ lymphocytes to promote immunosuppression through both B7-dependent and B7-independent pathways. The B7-1 (CD80) and B7-2 (CD86) proteins found on the surface of antigen presenting cells (APCs) interact with $\mathrm{CD} 28$ receptors on $\mathrm{T}$ cells to provide the costimulatory "Signal 2" for T cell activation ("Signal 1" being the primary interaction of the T cell receptor [TCR] and Major Histocompatibility Complex [MHC]). Though the B7:CD28 pathway is one of the best-understood mechanisms for $\mathrm{T}$ cell costimulation, it is complicated by the addition of CTLA- 4 (CD152), a lymphocyte surface protein with $30 \%$ homology to CD28 [26]. This transmembrane glycoprotein is a negative $\mathrm{T}$ cell regulator that also associates with $\mathrm{B} 7$, but with nearly 20 times greater affinity. CTLA-4:B7 engagement not only is quick and effective, but also segregates and prevents B7 from interacting with the activating CD28 [27-29].

B7-dependent immunosuppression occurs through direct engagement of CTLA-4, which may be expressed in a constitutive or rapidly inducible manner on $\mathrm{CD} 4+, \mathrm{CD} 8+$, and regulatory $\mathrm{T}$ cells (Tregs) [30]. Though the exact signaling mechanism for $\mathrm{T}$ cell inactivation has not yet been fully characterized, existing evidence suggests that upon phosphorylation, CTLA-4 binds to phosphoinositide 3-kinase (PI3K) via a Tyr-Val-Lys-Met (YVKM) motif and activates phosphatases SHP2 and PP2A. Downstream effects of the proposed signaling cascades (see Figure 3 ) may include inhibition of metabolism [31,32], inactivation of transcription factors [33, 34], inhibition of CD28-mediated lipid raft formation, [35, 36], and loss of calcium mobilization required for cell proliferation [37].

As an effector molecule, CTLA-4 modulates the threshold for $\mathrm{T}$ cell activation [38]. Along with direct signal transduction, engagement with $\mathrm{B} 7$ has been shown to control rapid cell surface accumulation of CTLA-4 [39]. CTLA-4 may also actively capture and remove B7-1 (CD80) and B72 (CD86) proteins on the opposing APC through a process 
of transendocytosis, resulting in "signaling independent" negative $\mathrm{T}$ cell regulation [40, 41].

In vivo studies have highlighted the regulatory role that CTLA-4 may play in lymphoproliferation. Early lethality due to uncontrolled polyclonal CD4+ T cell expansion was demonstrated in CTLA-4-deficient mice, ostensibly resulting from dysregulated self-tolerance of peripheral autoantigens [42-44].

2.1.1. Preclinical Evidence. The role of CTLA-4 in glioma maintenance is complex and incompletely understood. While early characterizations of glioma tissue noted dramatic CD4+ lymphopenia and $\mathrm{T}$ cell anergy [45-47], the mechanisms by which gliomas achieved global immunocompromise were not yet known. Studies from the early 2000s implicated CTLA4 in the development of Tregs, a population of immune suppressor cells that is often expanded in gastric $[48,49]$, pancreatic [50, 51], ovarian [52], and lung cancers [52]. In 2006, using flow cytometry on human GBM samples, El Andaloussi and Lesniak demonstrated that the number of FOXP3+ Tregs were significantly increased in TIL populations compared to controls and that CTLA-4 expression was also elevated within the glioma Treg population compared to those in the control samples [8]. That same year, Fecci et al. reported their findings that while absolute $\mathrm{CD} 4+$ cell counts (including $\mathrm{CD} 4+\mathrm{T}$ helper cells and CD4+CD25+FoxP3+CD4RO+ Tregs) were lower in malignant glioma samples compared to controls, Tregs represented an increased fraction of the existing $\mathrm{T}$ cells, and though diminished in number, they were sufficient to significantly impair immune responsiveness [53]. These findings have helped implicate CTLA- 4 in the maintenance of an immunosuppressive tumor microenvironment and highlight its potential as a target for immunotherapy in malignant gliomas.

In a follow-up study by Fecci et al, monoclonal antiCTLA-4 antibody was administered in murine gliomabearing mice to investigate the immune consequences of CTLA-4 checkpoint blockade. A long-term survival of $80 \%$ was reported in the treated group, as well as a restoration of $\mathrm{CD} 4+$ proliferation and antitumor capacity. Interestingly, the treatment effects seemed to be exclusive to the CD4+ helper $\mathrm{T}$ cell compartment, while Tregs remained functionally unaffected or unsuppressed [9]. Additional animal studies explored the effects of combining anti-CTLA- 4 with other immunotherapies. Grauer et al. reported a 50\% survival with anti-CTLA- 4 alone, compared to $100 \%$ survival in mice treated with both anti-CTLA-4 and anti-CD25 (alpha chain of the IL-2 receptor) [54]. Agarwalla et al. found that while high dose anti-CTLA-4 alone was ineffective against large, well-established tumors, the addition of a whole tumor cell vaccination (Gvax) significantly improved long term survival in mice with murine intracranial gliomas [55]. Findings such as these have helped promote the development of clinical trials using anti-CTLA antibody for malignant gliomas.

2.1.2. Clinical Evidence. In light of promising results in animal models, clinical testing of two fully humanized antiCTLA-4 antibodies, ipilimumab (Bristol Meyer-Squibb) and tremelimumab (Pfizer), began in 2000. The findings from subsequent studies culminated in the $2011 \mathrm{FDA}$ approval of ipilimumab for the treatment of unresectable or metastatic melanoma $[3,6,41,56]$. With regard to GBM, The National Cancer Institute has begun a Phase I trial to identify safety and dosage of ipilimumab and/or nivolumab with temozolomide in newly diagnosed glioblastoma (NCT02311920). In addition, a randomized, 2-arm, Phase II-III study of ipilimumab in combination with standard-of-care temozolomide for the treatment of newly diagnosed glioblastoma is also currently underway, helmed by the Radiation Therapy Oncology Group (RTOG 1125) [57].

2.2. PD-1/PDL-1. Like CTLA-4, programmed cell death protein 1 (PD-1, also known as CD279) is an inhibitory receptor that negatively regulates the immune system. However, while CTLA-4 mainly affects naïve T cells, PD-1 is more broadly expressed on immune cells and regulates mature $\mathrm{T}$ cell activity in peripheral tissues and in the tumor microenvironment [41].

The PD-1 receptor binds two ligands, PD ligand 1 (PDL-1, also known as B7-H1 or CD274) and PDL2 (B7-DC or 273) [58-61], each belonging to the same B7 family as the B7-1 and B7-2 proteins that interact with CD28 and CTLA-4. In the first paper detailing the discovery of the ligand, Dong et al. noted that ligation of PDL-1 not only decreased IFN $\gamma$, TNF $\alpha$, and IL-2 production but also stimulated production of IL10, an anti-inflammatory cytokine associated with decreased $\mathrm{T}$ cell reactivity and proliferation as well as antigen-specific $\mathrm{T}$ cell anergy [58,60,61]. PDL2 ligation also results in $\mathrm{T}$ cell suppression, but where PDL-1-PD-1 interactions inhibits proliferation via cell cycle arrest in the G1/G2 phase [62], PDL2-PD-1 engagement has been shown to inhibit TCRmediated signaling by blocking B7:CD28 signals at low antigen concentrations and reducing cytokine production at high antigen concentrations [59].

Though both CTLA- 4 activity and PD-1 activity have immunosuppressive effects, $\mathrm{PD}-1$ relies on different signaling pathways and mechanisms to suppress the T cell inflammatory response and limit autoimmunity (Figure 4 ).

Ligation of this 288 -amino acid transmembrane receptor results in the dephosphorylation (and deactivation) of ZAP70 and the recruitment of SHP2. Upon binding PD-1, SHP-2 directly dephosphorylates PI3K, which inhibits downstream activation of Akt and thereby decreases production of inflammatory cytokine production and cell survival proteins (i.e., Bcl-xL) $[63,64]$. Of note, PD-1 activity may be countered or overcome by strong TCR signaling or concomitant CD28 [65] or IL-2 [66] costimulation, allowing recovery of cytokine production and cell survival [61].

2.2.1. Preclinical Evidence. PDL-1 has been shown to be highly expressed on multiple malignant gliomas, as compared to normal brain or benign tumor tissues [67-70]. The mechanism for ligand upregulation has been elucidated in part by Parsa et al., who found that loss of the phosphatase and tensin homolog (PTEN) led to increased PDL-1 gene transcription; furthermore, gliomas with wild-type PTEN were more likely 
TABLE 1: Immune checkpoint antibodies under clinical development.

\begin{tabular}{|c|c|c|c|}
\hline Target & Biological function & Agent & $\begin{array}{c}\text { Stage of clinical } \\
\text { development }\end{array}$ \\
\hline CTLA-4 & Inhibitory receptor & $\begin{array}{c}\text { Ipilimumab } \\
\text { Tremelimumab }\end{array}$ & $\begin{array}{c}\text { Phase I/II/III/IV } \\
\text { Phase I/II/III }\end{array}$ \\
\hline PD-1 & Inhibitory receptor & $\begin{array}{c}\text { Nivolumab (MDX1106, } \\
\text { BMS-936558) } \\
\text { Pembrolizumab (MK-3475) } \\
\text { Pidilizumab (CT-011) }\end{array}$ & $\begin{array}{c}\text { Phase I/II/III/IV } \\
\text { Phase I/II/III } \\
\text { Phase I/II }\end{array}$ \\
\hline PD-L1 & Ligand for PD-1 & $\begin{array}{c}\text { BMS935559 (MDX1105) } \\
\text { MPDL3280A } \\
\text { MEDI4736 } \\
\text { MSB0010718C }\end{array}$ & $\begin{array}{l}\text { Phase I } \\
\text { Phase I } \\
\text { Phase I } \\
\text { Phase I }\end{array}$ \\
\hline PD-1-positive T cells & PD-1 inhibitor & AMP-224 & Phase I \\
\hline LAG-3 & Inhibitory protein & IMP321 & Phase I/II (terminated) \\
\hline KIR & Inhibitory receptor & Lirilumab (IPH2101, BMS) & Phase I/II \\
\hline $4-1 \mathrm{BB}$ & Stimulatory receptor & Urelumab (BMS-663513) & Phase I \\
\hline GITR & Stimulatory receptor & TRX518 & Phase I \\
\hline TIM-3 & Inhibitory receptor & Anti-TIM-3 & Preclinical \\
\hline
\end{tabular}

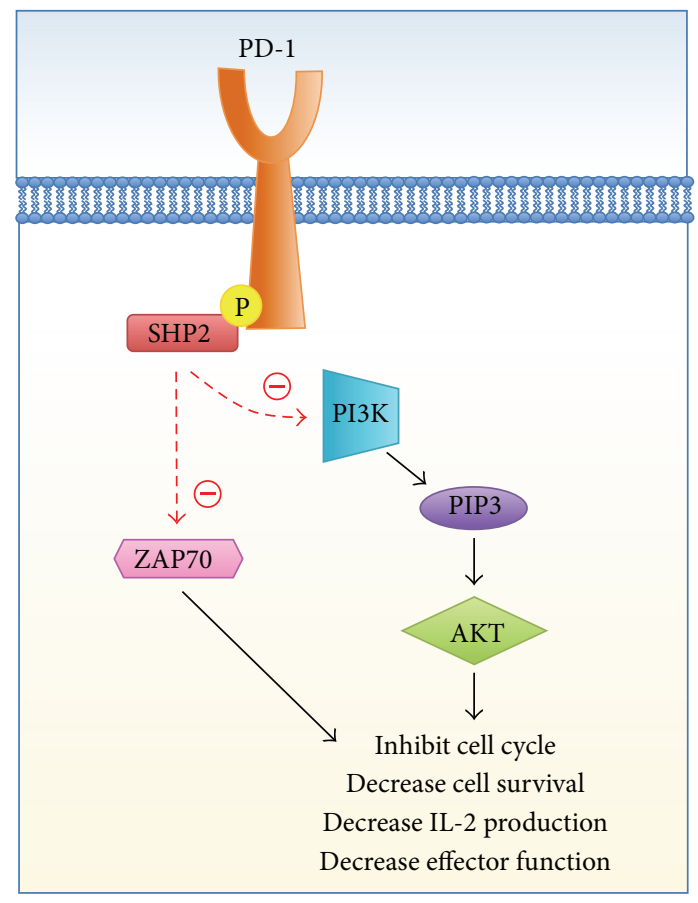

FIGURE 4: PD-1 signaling cascade.

to be lysed by tumor-specific T cells than gliomas with mutant or inactivated PTEN [68]. The presence of PDL-1 has been associated with potent inhibition of $\mathrm{CD} 4+$ and $\mathrm{CD} 8+\mathrm{T}$ cell activation and cytokine release (IFN $\gamma$, IL2, and IL10) [67]. PDL-1 expression levels have also been shown to have significant correlation with tumor grade [71]. Using a mouse orthotopic glioblastoma model, Zeng et al. demonstrated that the combined used of anti-PD-1 and focal radiation therapy led to robust antitumor activity and immunologic memory, as demonstrated by significantly improved survival, increased tumor infiltration of CD8+ T cells, and decreased Tregs populations [5]. These findings have spurred interest in further testing of PD-1 blockade in the clinical trials setting.

2.2.2. Clinical Evidence. At present, several forms of monoclonal anti-PD-1 and anti-PDL-1 antibodies are undergoing clinical development, several of which have shown promising results in early Phase I and II trials (Table 1).

Therapeutic IgGs that target the PD-1 receptor include AMP-224 (Amplimmune), Pembrolizumab (Merck), Nivolumab (BMS), and Pidilizumab (CureTech). Human IgGs targeting the PDL-1 ligand include BMS-936559 (BMS), MEDI4736 (Medimmune), MPDL3280A (Genentech), and MSB0010718C (Merck); additionally, rHigM12B7 (Mayo Foundation) is a human IgM that targets the PDL2 ligand.

Recent results from a clinical trial examining the safety and efficacy of Nivolumab with and without ipilimumab have shown that monotherapy with Nivolumab had fewer treatment related adverse effects than combination therapy and that immune therapy seems to have biologic effects. This has led to Phase III of the trial comparing the safety and efficacy of Nivolumab versus Bevacizumab with or without ipilimumab (NCT02017717). There are several clinical trials recruiting patients to study the effects of antiPD-1 in patients with GBM. These trials include a Phase I/II clinical trial (NCT01952769) to study the safety and efficacy of Pidilizumab in diffuse intrinsic pontine glioma and relapsed GBM, a Phase II trial of neoadjuvant Nivolumab in primary and recurrent GBM (NCT02550249), a Phase II trial of Pembrolizumab in recurrent GBM (NCT02337686), and several trials examining the effects of combination therapy of anti-PD-1 antibodies with Temozolomide with and without radiation therapy (NCT02311920, NCT02530502), INCB24360 (NCT02327078), FPA008 (NCT02526017), and dendritic cell vaccine (NCT02529072). 


\section{Additional Checkpoints}

3.1. LAG-3. Lymphocyte-activation gene 3 (LAG-3, also known as CD223) is a CD4-related transmembrane protein that competitively binds MHC II and acts as a coinhibitory checkpoint for $\mathrm{T}$ cell activation $[72,73]$. The mechanism by which LAG-3 negatively regulates the TCR-CD3 complex and inhibits $\mathrm{T}$ cell proliferation and cytokine production is not well understood, but several studies have suggested that the inhibitory function depends on a conserved KIEELE motif in the protein's cytoplasmic domain [72-74]. An additional domain binds LAP (LAG-3-associated protein), which may play a role in microtubule association after TCR engagement [75].

LAG-3 is expressed in vivo on the surface of activated CD4+, CD8+, and NK cells $[75,76]$ under inflammatory conditions. In vitro studies have shown that LAG-3 is upregulated by IL12 and promotes the production of IFN $\gamma$ [77]. LAG-3 expression is required for maximal Treg function, and ectopic expression may be sufficient for inducing regulatory activity, with suppressive capacities comparable to ectopically expressed FOXP3 [78, 79]. LAG-3 may also play a role in regulating DC function; engagement with DC MHCII molecules has been shown to induce morphologic changes and upregulate IL12 and TNF $\alpha$ secretion [76]. In a study by Workman and Vignali, LAG-3(-/-) T cells exhibited the following characteristics as compared to LAG-3+ cells: (1) delayed cell cycle arrest after stimulation with a superantigen, (2) greater proliferation after in vivo stimulation, (3) and higher numbers of memory $\mathrm{T}$ cells after viral exposure [73]. These data suggested LAG-3 plays an important role in regulating $\mathrm{T}$ cell expansion, a hypothesis that was further supported by a study by Huang et al. Using LAG-3 knockout mice, the authors demonstrated that, compared to wild-type Tregs, more than double the number of LAG-3(-/-) Tregs were required to control $\mathrm{CD} 4+$ helper $\mathrm{T}$ cell proliferation at high antigen peptide concentrations; furthermore, the authors reported that administration of anti-LAG-3 antibodies resulted in a reversal of Treg-mediated immune suppression [78]. Grosso et al. also employed antibodies against LAG-3 to increase proliferation and effector function of tumor-specific CD8+ cytotoxic T cells and resulting in disrupted tumor architecture and growth inhibition [80]. A recent study by Woo et al. demonstrated the efficacy of combined checkpoint blockade using three distinct tumor types (B16 melanoma, MC38 colorectal adenocarcinoma, and SalN fibrosarcoma); in each of these tumors types, tolerized $\mathrm{T}$ cells were found to coexpress LAG-3 and PD-1. Whereas treatment with anti-LAG-3 alone or anti-PD-1 alone delayed tumor growth in a minority of treated mice $(0-40 \%)$, dual therapy with anti-LAG-3 and anti-PD-1 resulted in complete tumor regression in 70 and $80 \%$ of mice with fibrosarcoma and colorectal tumors, respectively. Though no therapeutic effects were observed in the melanoma-inoculated mice, these findings provided compelling evidence for a synergistic benefit of combination checkpoint blockade [81]

3.2. TIM-3. $\mathrm{T}$ cell immunoglobulin mucin 3 (TIM-3) was discovered in 2002 as a marker of IFN $\gamma$ producing $\mathrm{CD} 4+$ and
CD8+ T cells in mice and humans $[82,83]$. A type I glycoprotein receptor that binds to S-type lectin galectin-9 (Gal9), TIM-3, is a widely expressed ligand on lymphocytes, liver, small intestine, thymus, kidney, spleen, lung, muscle, reticulocytes, and brain tissue [84]. Binding of Gal-9 by the TIM-3 receptor triggers downstream signaling to negatively regulate $T$ cell survival and function. In vitro studies have shown that Gal-9 induced TIM-3 activation induced intracellular calcium influx, aggregation, and cell death (mixed apoptosis and necrosis) of CD4+ T cells; additionally, Gal-9 administration in vivo can cause rapid elimination of IFN $\gamma$-producing $\mathrm{CD} 4+$ $\mathrm{T}$ cells and suppress Th1-mediated autoimmunity [85].

TIM-3 is a marker of CD8+ T cell exhaustion in the setting of chronic viral infections and immunogenic tumor microenvironments [82, 86-90]. TIM-3+PD-1+ TILs have been identified in murine models of colon adenocarcinoma, breast adenocarcinoma, and melanoma; coexpression of these two T cell "exhaustion" markers has been shown to be the most functionally impaired group of CD8+ TIL populations as determined by lowest IL2, TNF and IFN $\gamma$ production and progression through the cell cycle [90, 91]. In advanced AML tumor models where PD-1+TIM-3+ CD8+ cells have been correlated with disease progression, dual therapy with anti-PDL-1 and TIM-3Ig has been shown to significantly decrease tumor burden and improve survival [86].

Recent evidence suggests that TIM-3 may also play a role in myeloid-derived suppressor cell (MDSC) development. Composed of a heterogeneous group of CD11b+Gr1+ myeloid cells, MDSCs are powerful $\mathrm{T}$ cell suppressors that have been shown to proliferate under conditions of infection, autoimmunity, trauma, and malignancy, and their presence has been identified as negative predictive factor predictor for oncologic outcomes [10]. Both Gal-9 and transgenic TIM-3 overexpression have been shown to induce MDSC expansion, with subsequent $\mathrm{T}$ cell inhibition [92]; conversely, tumor growth was found to be significantly delayed in TIM-3(-/-) mice implanted with T1 mammary adenocarcinoma, as compared to TIM-3+ wild type mice [92].

3.3. KIR. Killer immunoglobulin-like receptors (KIRs) comprise a diverse repertoire of MHCI binding molecules that negatively regulate NK function to protect cells from NKmediated cell lysis. KIRs are generally expressed on NK cells but have also been detected on tumor specific CTLs [93]. Members of the KIR family of molecules contain 23 Ig ectodomains and cytoplasmic tails of variable length [94]. While some "noninhibitory" KIRs have truncated cytoplasmic tails, others possess longer tails containing two immune receptor tyrosine-based inhibitory motifs (ITIMs) that mediate downstream signaling and confer anti-NK potential [95-98]. The KIR locus is most likely polymorphic and polygenic, with inhibitory KIR haplotypes remaining relatively specific for HLA-B and HLA-C ligands, while noninhibitory phenotypes display greater variability [99].

Unlike adaptive B and T cells, NK cells lack such meticulous antigen sensitivity and instead rely on several activating and inhibitory receptors to modulate and direct their killing capacity [100]. When expressed on the cell surface, KIRs may 
play a role in inducing NK tolerance through a process of "licensing," in which each inhibitory receptor recognizes a self HLA class I molecule and prevents NK activation against autoantigens and self-tissue [101, 102]. Knowledge of these germline-encoded receptors has provided valuable insight into the mechanisms of NK-tumor interactions $[103,104]$. The phenomenon of NK-dependent rejection of syngeneic or human solid and hematopoietic tumor grafts $[105,106]$ is partially explained by the "missing" self-recognition phenomenon, where NK cells have been found to target aberrant cells that specifically lack self MHC I expression [107-109]. Though controversial, a few studies have also demonstrated that a lack of KIR ligands or KIR ligand incompatibility with foreign tissues is associated with improved survival and lower relapse rates [110-112] and suggest KIR inhibition as a viable means of enabling or augmenting NK cell-mediated antitumor lytic activity. This hypothesis has been borne out in adoptive transfer experiments of KIR-ligand mismatched or KIR-ligand nonexpressing NK cells which led to significantly increased cytotoxicity of multiple tumor cell lines [113, 114]. KIR blockade using anti-KIR antibodies has also been shown to prevent tolerogenicity and reconstitute NK-mediated cell lysis in both in vivo and in vitro hematopoietic cancer models [115-117].

3.4. $41 B B$. A member of the tumor necrosis factor (TNF) receptor superfamily that includes the FAS receptor (apoptosis antigen), CD40 ( $\mathrm{T}$ cell costimulatory receptor), CD27 (TNF receptor), and $\mathrm{CD} 30$ (tumor marker), and 4-1BB (CD137) is a Type II transmembrane glycoprotein [118] that is inducibly expressed on primed CD4+ and CD8+ T cells [119], activated NK cells, DCs, and neutrophils [120] and acts as a T cell costimulatory molecule when bound to the 4-1BB ligand (4$1 \mathrm{BBL}$ ) found on activated macrophages, B cells, and DCs [121, 122]. Ligation of the 4-1BB receptor leads to activation of the NF- $\kappa$ B, c-Jun and p38 signaling pathways [123] and has been shown to promote survival of CD8+ T cells, specifically, by upregulating expression of the antiapoptotic genes $\mathrm{BcL}-\mathrm{x}(\mathrm{L})$ and Bfl-1 [124]. In this manner, 4-1BB serves to boost or even salvage a suboptimal immune response [120]. Its expression may also be contingent on activation of the $\mathrm{B} 7: \mathrm{CD} 28$ pathway (see above section on CTLA-4), with 4-1BB producing its own feedforward loop to maintain T cell activity, and the B7-CD28 complex serving to temper the immune response and protect against inappropriate immune activation [21].

Unlike negative $\mathrm{T}$ cell regulators (i.e., CTLA-4, PD-1, LAG-3, and TIM-3), 4-1BB is an activating checkpoint that mediates prosurvival and proinflammatory signaling pathways. 4-1BB costimulation has been shown to profoundly enhance antigen-specific CD8 T cell survival and proliferation [125] and has therefore become a target of interest in tumor immunotherapy, especially against poorly immunogenic tumors for which the host antitumor immune response may prove inadequate. Monoclonal agonist antibodies are one promising method of harnessing the proinflammatory potential of this checkpoint molecule. Anti-4-1BB antibodies have been shown to cause tumor regression in animal models of sarcoma and mastocytoma [119], breast cancer [126], and metastatic colon carcinoma [127] with concomitant increase in tumor selective cytotoxic T cell activity. Synergy with IL12 gene therapy and anti-4-1BB antibody [127] or local 4$1 \mathrm{BB}$ gene [126] delivery has also been shown with significant tumor rejection and long-term immunity seen in metastatic breast and colon cancer models. In intracranial tumor models, anti-41BB has been shown to have moderate cure rates (2/5 mice with GL261 glioma and 4/5 with MCA205 sarcoma), but no effect against the poorly immunogenic B16/D5 melanoma model [128]. Adoptive transfer experiments have also been used to highlight 4-1BB's role in antitumor immunity. CD28 and 4-1BB costimulated T cells adoptively transferred into mice bearing poorly immunogenic melanoma have been shown to result in a $60 \%$ cure rate [129] and prolong survival in murine fibrosarcoma models [130]. Whole cell vaccines using tumor cells transfected with $4-1 \mathrm{BBL}$ cDNA have also been shown to induce vigorous antitumor CD8+ T cell activity and long term survival in various tumor models [131-134]. However, the technical difficulty and feasibility of culturing and administering lymphocyte or transfected tumor cells for either adoptive transfer or whole cell vaccination have limited their translation into clinical practice.

3.5. GITR. Glucocorticoid-induced TNFR family related gene (GITR) is a member of the tumor necrosis factor receptor (TNFR) superfamily that is constitutively or conditionally expressed on Treg, CD4, and CD8 T cells [135, 136]. Initially described as a unique CD4+CD25+FoxP3+ Treg marker [137], subsequent studies demonstrated rapid upregulation of GITR on effector $\mathrm{T}$ cells following TCR ligation and activation [138-142]. The human GITR ligand (GITRL) is constitutively expressed on APCs in secondary lymphoid organs and has also been found on nonlymphoid tissues including vascular endothelial and various epithelial cells $[135,143]$. The downstream effect of GITR:GITRL interaction is believed to be at least twofold, including (1) attenuation of Treg activity and (2) enhancement of CD4+ $\mathrm{T}$ cell activity $[137-139,141,144,145]$. The net result is a reversal of Treg-mediated immunosuppression and increased immune stimulation $[142,146]$.

Like the $4-1 \mathrm{BB}$ costimulatory molecule, GITR is an activating checkpoint that enhances inflammatory pathways and host immune response. Overexpression or experimental GITR agonism is associated with autoimmunity $[138,140$, 147] and pathologic inflammatory responses such as in asthma [148] and post-stroke states [149]. Preclinical studies have elucidated the differential effects of GITR upregulation on Tregs versus effector T lymphocytes, and its potential role in facilitating the antitumor immune response. Using antiGITR monoclonal antibodies, Cohen et al. demonstrated that GITR agonism led to lower intratumoral Treg accumulation, loss of FoxP3 expression, decreased Treg suppressor function, and, ultimately, regression of B16 melanoma in mouse models [150]. While these findings were initially implicated Tregs as the primary substrate for GITR:GITRL interactions, subsequent studies have suggested that effector $\mathrm{T}$ cells, as opposed to Tregs, may be the principal mediators of the GITR signaling pathway [139-141]. Using GITR knockout mice that still 
retained functional Treg populations, Stephens et al. elegantly demonstrated that GITR engagement on CD4+CD25- T cells, and not CD25+ Treg cells, was required to abrogate Treg suppressive activity [151]. Conversely, antagonizing GITRL using blocking antibodies seemed to increase CD4+ T cell susceptibility to Treg-mediated suppression [151]. Additional studies that demonstrated the efficacy of anti-GITR agonist antibodies in inducing tumor regression and preventing regrowth upon secondary challenge have raised interest in GITR as a potential target of tumor immunotherapy $[138,152$, 153].

3.5.1. Clinical Evidence. At present, there are no clinical trials for GBM involving IMP321 (a soluble LAG-3 chimeric IgG1 and MHCII agonist), anti-TIM-3 antibody, IPH2101 (antiKIR), BMS-663513 (a fully humanized anti-4-1BB agonist antibody), or TRX518 (a first in class, humanized anti-GITR monoclonal antibody). However, these immune modulators have tremendous therapeutic potential for the treatment of CNS tumors.

\section{Integrating Checkpoint Inhibitors into the Standard of Care}

Despite aggressive treatment with chemotherapy and radiation, the refractory nature of high-grade gliomas has become strong motivation to seek novel treatment regimens. The clinical successes of immunomodulating antibodies in both CNS and non-CNS cancers have raised the possibility of adding checkpoint inhibitors to the current anticancer armamentarium as a complementary or even synergistic modality.

Unlike vaccine therapies or adoptive cell transfer, checkpoint inhibition is a nonspecific strategy that relies on generalized activation of the immune system. While $\mathrm{T}$ cells are the best-characterized targets of checkpoint inhibition at present, it is becoming clear that these therapies have wide-ranging effects on other immune players such as NK cells, monocytes, macrophages, and dendritic cells $[78,100$, 154, 155] (Figure 2). Nonspecific checkpoint-based therapies may therefore benefit from concurrent therapies that either deplete immunosuppressive cells (i.e., chemotherapy) or increase access to tumor-specific antigens (i.e., ionizing radiation).

The following discussion will focus on the possible synergistic effects of concurrent chemoradiation therapy and the challenges of integrating checkpoint inhibitors into the current standard of care.

4.1. Checkpoint Inhibitors and Radiation Therapy. RT is a nonselective cytocidal treatment modality that targets rapidly dividing cells. $\mathrm{T}$ cells, which are the main effectors of cancer immunotherapy, are known to be exquisitely sensitive to its effects $[156,157]$. Studies testing combined RT and TMZ [158] or RT and steroid [47] regimens have demonstrated significant, long-lasting drops in CD4 counts with concomitant systemic immune compromise. Though these findings could suggest an antagonistic interaction between RT and immunotherapy, the significant cellular and stromal destruction caused by ionizing radiation has been shown to act as a powerful "danger," or activation, signal to the host immune system [159, 160]. Apoptotic tumor cells provide APCs with tumor-specific antigens that can be presented on MHC class I molecules to CD8+ cells, leading to enhanced, antitumor immune activation [161-163]. RT has also been shown to counteract MHC downregulation, a strategy used by GBM to escape immune detection $[164,165]$; a study by Newcomb et al. reported a significant upregulation of the $\beta 2$ microglobulin light chain subunit of the MHCI molecule in GL261 glioma cells following whole body radiation therapy [166].

Elucidating the pathways for radiation-induced immune stimulation provides a mechanism for the observed synergy between radiation and immunotherapy. Prolonged survival with the addition of anti-CTLA- 4 to stereotactic radiosurgery has been reported in breast cancer-bearing mice, largely attributed to CD8+ T cell activity [167]. Although it has not been seen in GBM, combination therapy with ipilimumab (anti-CTLA-4 antibody) and local radiation has also been shown to cause tumor regression at both irradiated and nonirradiated sites-the latter known as the abscopal effect $[168,169]$. Zeng et al. demonstrated that the addition of SRS to PD-1 blockade increased in vitro expression of proinflammatory molecules such as MHCI, CXCL16, and ICAM and correlated with a survival advantage in glioma-bearing mice [5]. The results of these preclinical studies indicate that RT can work synergistically with checkpoint inhibitors, and at present, a Phase I trial is underway testing the combined used of Pembrolizumab and radiation in GBM (NCT02530502). Results from these studies will help guide future strategies to integrate immunotherapy into the current standard of care therapeutic regimen.

4.2. Checkpoint Inhibitors and Chemotherapy. Approved by the FDA in 2001 for refractory anaplastic astrocytomas and in 2005 for newly diagnosed GBMs, TMZ is a secondgeneration DNA alkylating agent that is currently the chemotherapeutic standard for the treatment of malignant gliomas. Since its adoption as a first-line agent, population studies have demonstrated an increase in 2-year survival from 7\% in cases that were diagnosed between 1993 and 1995 to $17 \%$ in those diagnosed between 2005 and 2007 [170]. Use of TMZ in combination with radiation has also been shown to increase two-year survival from $10.4 \%$ to $26.5 \%$, as compared to radiation monotherapy [171].

Chemotherapy has been widely hypothesized to be antagonistic or counterproductive to immunotherapy due to its systemic immune toxic effects. Cytotoxic drugs such as TMZ have been associated with severe lymphopenia [172, 173]. In a prospective, multicenter study of patients with highgrade gliomas, Grossman et al. observed long-lasting, systemic CD4+ lymphodepletion with poor clinical outcomes in patients who underwent treatment with oral TMZ and radiation. In this study, median CD4 count was 664 cells $/ \mathrm{mm}^{3}$ before treatment, reached its lowest point at 255 cells $/ \mathrm{mm}^{3}$ two months after the start of TMZ + RT, and remained persistently low for the duration of observation (12 months) [158]. 
In theory, these effects-in combination with the locally immunosuppressive tumor microenvironment-could abrogate immunotherapy's efficacy by depleting the peripheral pool of effector T cells.

Contrary to these suppositions, numerous clinical studies combining chemotherapy with immunotherapy such as monoclonal antibodies, active specific immunotherapy, and adoptive lymphocyte immunotherapy have shown promising results, though larger studies are needed to verify and assess efficacy [174]. Heimberger et al. published a case study in 2008 demonstrating successful immune activation in a GBM patient following treatment with both TMZ and EGFRvIII vaccine [7]. Of note, the authors observed no significant decline in CD4+ and CD8+ T cell counts and concluded that as long as the cytotoxic chemotherapy was administered outside of the vaccine's therapeutic window, the two modalities could be used in a synergistic manner [7]. Furthermore, some authors have suggested the use of local or intratumoral TMZ as a less immunosuppressive alternative compared to oral TMZ. Using glioma-bearing mice, Brem et al. found that polymeric implants for local TMZ delivery were associated with improved survival, and that the addition of RT prolonged survival even further without additional toxicity [175]. Fritzell et al. later demonstrated that intratumoral TMZ may synergistically increase survival rates in immunized mice by sustained proliferation of CD8 $+\mathrm{T}$ cells and decreased intratumoral immunosuppressive cells such as myeloid-derived suppressor cells (MDSCs) [176].

With respect to checkpoint inhibitors, these findings imply that carefully timed, interdigitated or alternating chemotherapy would not only protect immunotherapyactivated effector $\mathrm{T}$ cells but also ablates immunosuppressive Tregs that could otherwise reduce the efficacy of immunomodulating antibodies $[7,177]$. The use of intratumoral chemotherapy may also further protect the effector $\mathrm{T}$ cells and provide a survival advantage due to a more robust immune profile. At present, there are no published clinical trials data on the use of TMZ plus checkpoint inhibitors. Further preclinical and clinical studies will be required to examine the risks and benefits of this particular multimodal therapeutic strategy.

\section{Summary}

Immune checkpoint therapy has emerged as a welcome and potent addition to the current arsenal of anticancer treatment. While certain checkpoint blockades such as CTLA-4 and PD-1 have proven clinically successful, both alone and in conjunction with each other, there are several other targets that such as LAG-3, TIM-3, KIR, and GITR that have shown promise for passive immunotherapy. Anti-CTLA-4 and antiPD-1 have had promising outcomes in preclinical studies for the treatment of malignant GBMs. Those studies have spurred further ongoing clinical trials that look to solidify immune therapy as a mainstay for treating primary and recurrent brain tumors. Checkpoint inhibitors may be effective not only as monotherapy, but also in combination with chemotherapy and/or radiation therapy. Synergy between the antibodies and either of the two conventional modalities could lead to significant improvements in tumor regression and overall survival. Further research on the mechanisms and therapeutic efficacy of specific antibodies, as well as their interactions with other treatment modalities, is needed to successfully incorporate checkpoint modulators into the current standard of care.

\section{Conflict of Interests}

The authors declare that there is no conflict of interests regarding the publication of this paper.

\section{Authors' Contribution}

Eileen S. Kim and Jennifer E. Kim contributed equally to this work.

\section{References}

[1] J. R. Brahmer, S. S. Tykodi, L. Q. M. Chow et al., "Safety and activity of anti-PD-L1 antibody in patients with advanced cancer," The New England Journal of Medicine, vol. 366, no. 26, pp. 2455-2465, 2012.

[2] D. T. Le, J. N. Uram, H. Wang et al., "PD-1 blockade in tumors with mismatch-repair deficiency," The New England Journal of Medicine, vol. 372, no. 26, pp. 2509-2520, 2015.

[3] F. S. Hodi, S. J. O’Day, D. F. McDermott et al., "Improved survival with ipilimumab in patients with metastatic melanoma," The New England Journal of Medicine, vol. 363, no. 8, pp. 711723, 2010.

[4] J. D. Wolchok, H. Kluger, M. K. Callahan et al., "Nivolumab plus Ipilimumab in advanced melanoma," The New England Journal of Medicine, vol. 369, no. 2, pp. 122-133, 2013.

[5] J. Zeng, A. P. See, J. Phallen et al., "Anti-PD-1 blockade and stereotactic radiation produce long-term survival in mice with intracranial gliomas," International Journal of Radiation Oncology Biology Physics, vol. 86, no. 2, pp. 343-349, 2013.

[6] F. Aranda, E. Vacchelli, A. Eggermont et al., "Trial watch: immunostimulatory monoclonal antibodies in cancer therapy," Oncoimmunology, vol. 3, no. 1, Article ID e27297, 2014.

[7] A. B. Heimberger, W. Sun, S. F. Hussain et al., "Immunological responses in a patient with glioblastoma multiforme treated with sequential courses of temozolomide and immunotherapy: case study," Neuro-Oncology, vol. 10, no. 1, pp. 98-103, 2008.

[8] A. El Andaloussi and M. S. Lesniak, "An increase in $\mathrm{CD} 4+\mathrm{CD} 25+\mathrm{FOXP} 3+$ regulatory $\mathrm{T}$ cells in tumor-infiltrating lymphocytes of human glioblastoma multiforme," NeuroOncology, vol. 8, no. 3, pp. 234-243, 2006.

[9] P. E. Fecci, H. Ochiai, D. A. Mitchell et al., "Systemic CTLA-4 blockade ameliorates glioma-induced changes to the $\mathrm{CD} 4^{+} \mathrm{T}$ cell compartment without affecting regulatory T-cell function," Clinical Cancer Research, vol. 13, no. 7, pp. 2158-2167, 2007.

[10] D. I. Gabrilovich and S. Nagaraj, "Myeloid-derived suppressor cells as regulators of the immune system," Nature Reviews Immunology, vol. 9, no. 3, pp. 162-174, 2009.

[11] A. P. See, J. E. Han, J. Phallen et al., "The role of STAT3 activation in modulating the immune microenvironment of GBM," Journal of Neuro-Oncology, vol. 110, no. 3, pp. 359-368, 2012. 
[12] C. Jackson, J. Ruzevick, A. G. Amin, and M. Lim, "Potential role for STAT3 inhibitors in glioblastoma," Neurosurgery Clinics of North America, vol. 23, no. 3, pp. 379-389, 2012.

[13] M. Kortylewski and H. Yu, "Stat3 as a potential target for cancer immunotherapy," Journal of Immunotherapy, vol. 30, no. 2, pp. 131-139, 2007.

[14] A. Louveau, I. Smirnov, T. J. Keyes et al., "Structural and functional features of central nervous system lymphatic vessels," Nature, vol. 523, no. 7560, pp. 337-341, 2015.

[15] R. I. von Hanwehr, F. M. Hofman, C. R. Taylor, and M. L. J. Apuzzo, "Mononuclear lymphoid populations infiltrating the microenvironment of primary CNS tumors. Characterization of cell subsets with monoclonal antibodies," Journal of Neurosurgery, vol. 60, no. 6, pp. 1138-1147, 1984.

[16] L. Palma, N. Di Lorenzo, and B. Guidetti, "Lymphocytic infiltrates in primary glioblastomas and recidivous gliomas. Incidence, fate, and relevance to prognosis in 228 operated cases," Journal of Neurosurgery, vol. 49, no. 6, pp. 854-861, 1978.

[17] W. H. Brooks, W. R. Markesbery, G. D. Gupta, and T. L. Roszman, "Relationship of lymphocyte invasion and survival of brain tumor patients," Annals of Neurology, vol. 4, no. 3, pp. 219224, 1978.

[18] D. K. Boker, R. Kalff, F. Gullotta, S. Weekes-Seifert, and U. Möhrer, "Mononuclear infiltrates in human intracranial tumors as a prognostic factor. Influence of preoperative steroid treatment. I. Glioblastoma," Clinical Neuropathology, vol. 3, no. 4, pp. 143-147, 1984.

[19] D. Schiffer, D. Cavicchioli, M. T. Giordana, L. Palmucci, and A. Piazza, "Analysis of some factors effecting survival in malignant gliomas," Tumori, vol. 65, no. 1, pp. 119-125, 1979.

[20] Y.-F. Yang, J.-P. Zou, J. Mu et al., "Enhanced induction of antitumor T-cell responses by cytotoxic $\mathrm{T}$ lymphocyte-associated molecule-4 blockade: the effect is manifested only at the restricted tumor-bearing stages," Cancer Research, vol. 57, no. 18, pp. 4036-4041, 1997.

[21] Y.-J. Kim, S. H. Kim, P. Mantel, and B. S. Kwon, "Human 4-1BB regulates CD28 co-stimulation to promote Th1 cell responses," European Journal of Immunology, vol. 28, no. 3, pp. 881-890, 1998.

[22] G. P. Dunn, A. T. Bruce, H. Ikeda, L. J. Old, and R. D. Schreiber, "Cancer immunoediting: from immunosurveillance to tumor escape," Nature Immunology, vol. 3, no. 11, pp. 991-998, 2002.

[23] R. D. Schreiber, L. J. Old, and M. J. Smyth, "Cancer immunoediting: integrating immunity's roles in cancer suppression and promotion," Science, vol. 331, no. 6024, pp. 1565-1570, 2011.

[24] S. L. Topalian, C. G. Drake, and D. M. Pardoll, "Targeting the PD-1/B7-H1(PD-L1) pathway to activate anti-tumor immunity," Current Opinion in Immunology, vol. 245, no. 2, pp. 207-212, 2012.

[25] R. J. Greenwald, G. J. Freeman, and A. H. Sharpe, "The B7 family revisited," Annual Review of Immunology, vol. 23, pp. 515-548, 2005.

[26] M.-L. Alegre, K. A. Frauwirth, and C. B. Thompson, “T-cell regulation by CD28 and CTLA-4," Nature Reviews Immunology, vol. 1, no. 3, pp. 220-228, 2001.

[27] A. V. Collins, D. W. Brodie, R. J. C. Gilbert et al., "The interaction properties of costimulatory molecules revisited," Immunity, vol. 17, no. 2, pp. 201-210, 2002.

[28] P. S. Linsley, J. L. Greene, W. Brady, J. Bajorath, J. A. Ledbetter, and R. Peach, "Human B7-1 (CD80) and B7-2 (CD86) bind with similar avidities but distinct kinetics to CD28 and CTLA-4 receptors," Immunity, vol. 1, no. 9, pp. 793-801, 1994.
[29] R. J. Peach, J. Bajorath, W. Brady et al., "Complementarity determining region 1 (CDR1)- and CDR3-analogous regions in CTLA-4 and CD28 determine the binding to B7-1," The Journal of Experimental Medicine, vol. 180, no. 6, pp. 2049-2058, 1994.

[30] T. Lindsten, K. P. Lee, E. S. Harris et al., "Characterization of CTLA- 4 structure and expression on human T cells," The Journal of Immunology, vol. 151, no. 7, pp. 3489-3499, 1993.

[31] C. E. Rudd, A. Taylor, and H. Schneider, "CD28 and CTLA-4 coreceptor expression and signal transduction," Immunological Reviews, vol. 229, no. 1, pp. 12-26, 2009.

[32] E. Chuang, T. S. Fisher, R. W. Morgan et al., "The CD28 and CTLA-4 receptors associate with the serine/threonine phosphatase PP2A," Immunity, vol. 13, no. 3, pp. 313-322, 2000.

[33] J. H. Fraser, M. Rincón, K. D. McCoy, and G. L. Gros, "CTLA4 ligation attenuates AP-1, NFAT and NF- $\kappa$ B activity in activated T cells," European Journal of Immunology, vol. 29, no. 3, pp. 838844, 1999.

[34] H. Bour-Jordan, J. H. Esensten, M. Martinez-Llordella, C. Penaranda, M. Stumpf, and J. A. Bluestone, "Intrinsic and extrinsic control of peripheral T-cell tolerance by costimulatory molecules of the CD28/B7 family," Immunological Reviews, vol. 241, no. 1, pp. 180-205, 2011.

[35] S. Chikuma, J. B. Imboden, and J. A. Bluestone, "Negative regulation of $\mathrm{T}$ cell receptor-lipid raft interaction by cytotoxic $\mathrm{T}$ lymphocyte-associated antigen 4," The Journal of Experimental Medicine, vol. 197, no. 1, pp. 129-135, 2003.

[36] M. Martin, H. Schneider, A. Azouz, and C. E. Rudd, "Cytotoxic T lymphocyte antigen 4 and CD28 modulate cell surface raft expression in their regulation of T cell function," Journal of Experimental Medicine, vol. 194, no. 11, pp. 1675-1681, 2001.

[37] H. Schneider, X. Smith, H. Liu, G. Bismuth, and C. E. Rudd, "CTLA-4 disrupts ZAP70 microcluster formation with reduced T cell/APC dwell times and calcium mobilization," European Journal of Immunology, vol. 38, no. 1, pp. 40-47, 2008.

[38] T. F. Gajewski, F. Fallarino, P. E. Fields, F. Rivas, and M.-L. Alegre, "Absence of CTLA-4 lowers the activation threshold of primed $\mathrm{CD}^{+}$TCR-transgenic T cells: lack of correlation with Src homology domain 2-containing protein tyrosine phosphatase," The Journal of Immunology, vol. 166, no. 6, pp. 39003907, 2001.

[39] M.-L. Alegre, P. J. Noel, B. J. Eisfelder et al., "Regulation of surface and intracellular expression of CTLA4 on mouse T cells," Journal of Immunology, vol. 157, no. 11, pp. 4762-4770, 1996.

[40] O. S. Qureshi, Y. Zheng, K. Nakamura et al., "Trans-endocytosis of CD80 and CD86: a molecular basis for the cell-extrinsic function of CTLA-4," Science, vol. 332, no. 6029, pp. 600-603, 2011.

[41] D. M. Pardoll, "The blockade of immune checkpoints in cancer immunotherapy," Nature Reviews Cancer, vol. 12, no. 4, pp. 252264, 2012.

[42] P. Waterhouse, J. M. Penninger, E. Timms et al., "Lymphoproliferative disorders with early lethality in mice deficient in Ctla-4," Science, vol. 270, no. 5238, pp. 985-988, 1995.

[43] C. A. Chambers, T. J. Sullivan, and J. P. Allison, "Lymphoproliferation in CTLA-4-deficient mice is mediated by costimulationdependent activation of $\mathrm{CD} 4^{+} \mathrm{T}$ cells," Immunity, vol. 7, no. 6, pp. 885-895, 1997.

[44] B. Salomon and J. A. Bluestone, "Complexities of CD28/B7: CTLA-4 costimulatory pathways in autoimmunity and transplantation," Annual Review of Immunology, vol. 19, pp. 225-252, 2001. 
[45] L. A. Morford, L. H. Elliott, S. L. Carlson, W. H. Brooks, and T. L. Roszman, "T cell receptor-mediated signaling is defective in T cells obtained from patients with primary intracranial tumors," Journal of Immunology, vol. 159, no. 9, pp. 4415-4425, 1997.

[46] T. L. Roszman and W. H. Brooks, "Immunobiology of primary intracranial tumours. III. demonstration of a qualitative lymphocyte abnormality in patients with primary brain tumours," Clinical \& Experimental Immunology, vol. 39, no. 2, pp. 395-402, 1980.

[47] M. A. Hughes, M. Parisi, S. Grossman, and L. Kleinberg, "Primary brain tumors treated with steroids and radiotherapy: low CD4 counts and risk of infection," International Journal of Radiation Oncology Biology Physics, vol. 62, no. 5, pp. 1423-1426, 2005.

[48] F. Ichihara, K. Kono, A. Takahashi, H. Kawaida, H. Sugai, and H. Fujii, "Increased populations of regulatory $\mathrm{T}$ cells in peripheral blood and tumor-infiltrating lymphocytes in patients with gastric and esophageal cancers," Clinical Cancer Research, vol. 9, no. 12, pp. 4404-4408, 2003.

[49] K. D. Lute, K. F. May Jr., P. Lu et al., "Human CTLA4 knockin mice unravel the quantitative link between tumor immunity and autoimmunity induced by anti-CTLA- 4 antibodies," Blood, vol. 106, no. 9, pp. 3127-3133, 2005.

[50] U. K. Liyanage, T. T. Moore, H.-G. Joo et al., "Prevalence of regulatory $\mathrm{T}$ cells is increased in peripheral blood and tumor microenvironment of patients with pancreas or breast adenocarcinoma," The Journal of Immunology, vol. 169, no. 5, pp. 2756-2761, 2002.

[51] T. Sasada, M. Kimura, Y. Yoshida, M. Kanai, and A. Takabayashi, " $\mathrm{CD}^{4+} \mathrm{CD} 25^{+}$regulatory $\mathrm{T}$ cells in patients with gastrointestinal malignancies: possible involvement of regulatory $\mathrm{T}$ cells in disease progression," Cancer, vol. 98, no. 5, pp. 1089-1099, 2003.

[52] E. Y. Woo, C. S. Chu, T. J. Goletz et al., "Regulatory CD $4^{+} \mathrm{CD} 25^{+}$ $\mathrm{T}$ cells in tumors from patients with early-stage non-small cell lung cancer and late-stage ovarian cancer," Cancer Research, vol. 61, no. 12, pp. 4766-4772, 2001.

[53] P. E. Fecci, D. A. Mitchell, J. F. Whitesides et al., "Increased regulatory T-cell fraction amidst a diminished CD4 compartment explains cellular immune defects in patients with malignant glioma," Cancer Research, vol. 66, no. 6, pp. 3294-3302, 2006.

[54] O. M. Grauer, S. Nierkens, E. Bennink et al., "CD4+FoxP3+ regulatory $\mathrm{T}$ cells gradually accumulate in gliomas during tumor growth and efficiently suppress antiglioma immune responses in vivo," International Journal of Cancer, vol. 121, no. 1, pp. 95-105, 2007.

[55] P. Agarwalla, Z. Barnard, P. Fecci, G. Dranoff, and W. T. Curry Jr., "Sequential immunotherapy by vaccination with GM-CSF-expressing glioma cells and CTLA-4 blockade effectively treats established murine intracranial tumors," Journal of Immunotherapy, vol. 35, no. 5, pp. 385-389, 2012.

[56] J. S. Weber, R. Dummer, V. de Pril, C. Lebbé, and F. S. Hodi, "Patterns of onset and resolution of immune-related adverse events of special interest with ipilimumab: detailed safety analysis from a phase 3 trial in patients with advanced melanoma," Cancer, vol. 119, no. 9, pp. 1675-1682, 2013.

[57] S. Tanaka, D. N. Louis, W. T. Curry, T. T. Batchelor, and J. Dietrich, "Diagnostic and therapeutic avenues for glioblastoma: no longer a dead end?” Nature Reviews Clinical Oncology, vol. 10, no. 1, pp. 14-26, 2013.

[58] H. Dong, G. Zhu, K. Tamada, and L. Chen, "B7-H1, a third member of the B7 family, co-stimulates T-cell proliferation and interleukin-10 secretion," Nature Medicine, vol. 5, no. 12, pp. 1365-1369, 1999.

[59] Y. Latchman, C. R. Wood, T. Chernova et al., "PD-L2 is a second ligand for PD-1 and inhibits T cell activation," Nature Immunology, vol. 2, no. 3, pp. 261-268, 2001.

[60] K. W. Moore, A. O'Garra, R. de Waal Malefyt, P. Vieira, and T. R. Mosmann, "Interleukin-10," Annual Review of Immunology, vol. 11, pp. 165-190, 1993.

[61] M. E. Keir, M. J. Butte, G. J. Freeman, and A. H. Sharpe, "PD1 and its ligands in tolerance and immunity," Annual Review of Immunology, vol. 26, pp. 677-704, 2008.

[62] N. Patsoukis, J. Brown, V. Petkova, F. Liu, L. Li, and V. A. Boussiotis, "Selective effects of PD-1 on Akt and ras pathways regulate molecular components of the cell cycle and inhibit $\mathrm{T}$ cell proliferation," Science Signaling, vol. 5, no. 230, article ra46, 2012.

[63] M. E. Keir, S. C. Liang, I. Guleria et al., "Tissue expression of PDL1 mediates peripheral T cell tolerance," Journal of Experimental Medicine, vol. 203, no. 4, pp. 883-895, 2006.

[64] R. V. Parry, J. M. Chemnitz, K. A. Frauwirth et al., "CTLA4 and PD-1 receptors inhibit T-cell activation by distinct mechanisms," Molecular and Cellular Biology, vol. 25, no. 21, pp. 9543-9553, 2005.

[65] G. J. Freeman, A. J. Long, Y. Iwai et al., "Engagement of the PD-1 immunoinhibitory receptor by a novel B7 family member leads to negative regulation of lymphocyte activation," The Journal of Experimental Medicine, vol. 192, no. 7, pp. 1027-1034, 2000.

[66] L. Carter, L. A. Fouser, J. Jussif et al., "PD-1:PD-L inhibitory pathway affects both $\mathrm{CD} 4^{+}$and $\mathrm{CD} 8^{+} \mathrm{T}$ cells and is overcome by IL-2," European Journal of Immunology, vol. 32, no. 3, pp. 634643, 2002.

[67] S. Wintterle, B. Schreiner, M. Mitsdoerffer et al., "Expression of the B7-related molecule B7-H1 by glioma cells: a potential mechanism of immune paralysis," Cancer Research, vol. 63, no. 21, pp. 7462-7467, 2003.

[68] A. T. Parsa, J. S. Waldron, A. Panner et al., "Loss of tumor suppressor PTEN function increases B7-H1 expression and immunoresistance in glioma," Nature Medicine, vol. 13, no. 1, pp. 84-88, 2007.

[69] T. Avril, S. Saikali, E. Vauleon et al., "Distinct effects of human glioblastoma immunoregulatory molecules programmed cell death ligand-1 (PDL-1) and indoleamine 2,3-dioxygenase (IDO) on tumour-specific T cell functions," Journal of Neuroimmunology, vol. 225, no. 1-2, pp. 22-33, 2010.

[70] J. F. M. Jacobs, A. J. Idema, K. F. Bol et al., "Regulatory T cells and the PD-L1/PD-1 pathway mediate immune suppression in malignant human brain tumors," Neuro-Oncology, vol. 11, no. 4, pp. 394-402, 2009.

[71] R. Wilmotte, K. Burkhardt, V. Kindler et al., "B7-homolog 1 expression by human glioma: a new mechanism of immune evasion," Neuroreport, vol. 16, no. 10, pp. 1081-1085, 2005.

[72] N. Li, C. J. Workman, S. M. Martin, and D. A. A. Vignali, "Biochemical analysis of the regulatory $\mathrm{T}$ cell protein lymphocyte activation gene-3 (LAG-3; CD223)," The Journal of Immunology, vol. 173, no. 11, pp. 6806-6812, 2004.

[73] C. J. Workman and D. A. A. Vignali, "The CD4-related molecule, LAG-3 (CD223), regulates the expansion of activated T cells," European Journal of Immunology, vol. 33, no. 4, pp. 970 979, 2003.

[74] S. Hannier, M. Tournier, G. Bismuth, and F. Triebel, "CD3/TCR complex-associated lymphocyte activation gene-3 molecules 
inhibit CD3/TCR signaling," The Journal of Immunology, vol. 161, no. 8, pp. 4058-4065, 1998.

[75] F. Triebel, "LAG-3: a regulator of T-cell and DC responses and its use in therapeutic vaccination," Trends in Immunology, vol. 24, no. 12, pp. 619-622, 2003.

[76] S. Andreae, F. Piras, N. Burdin, and F. Triebel, "Maturation and activation of dendritic cells induced by lymphocyte activation gene-3 (CD223)," The Journal of Immunology, vol. 168, no. 8, pp. 3874-3880, 2002.

[77] F. Annunziato, R. Manetti, L. Tomasévic et al., "Expression and release of LAG-3-encoded protein by human $\mathrm{CD} 4^{+} \mathrm{T}$ cells are associated with IFN- $\gamma$ production," The FASEB Journal, vol. 10, no. 7, pp. 769-776, 1996.

[78] C.-T. Huang, C. J. Workman, D. Flies et al., "Role of LAG-3 in regulatory T cells," Immunity, vol. 21, no. 4, pp. 503-513, 2004.

[79] M. V. Goldberg and C. G. Drake, "LAG-3 in cancer immunotherapy," Current Topics in Microbiology and Immunology, vol. 344, pp. 269-278, 2011.

[80] J. F. Grosso, C. C. Kelleher, T. J. Harris et al., "LAG-3 regulates $\mathrm{CD}^{+} \mathrm{T}$ cell accumulation and effector function in murine self- and tumor-tolerance systems," The Journal of Clinical Investigation, vol. 117, no. 11, pp. 3383-3392, 2007.

[81] S.-R. Woo, M. E. Turnis, M. V. Goldberg et al., "Immune inhibitory molecules LAG-3 and PD-1 synergistically regulate T-cell function to promote tumoral immune escape," Cancer Research, vol. 72, no. 4, pp. 917-927, 2012.

[82] K. Sakuishi, P. Jayaraman, S. M. Behar, A. C. Anderson, and V. K. Kuchroo, "Emerging Tim-3 functions in antimicrobial and tumor immunity," Trends in Immunology, vol. 32, no. 8, pp. 345349, 2011.

[83] C. Zhu, A. C. Anderson, and V. K. Kuchroo, "TIM-3 and its regulatory role in immune responses," Current Topics in Microbiology and Immunology, vol. 350, pp. 1-15, 2011.

[84] J. Wada and Y. S. Kanwar, "Identification and characterization of galectin-9, a novel $\beta$-galactoside-binding mammalian lectin," The Journal of Biological Chemistry, vol. 272, no. 9, pp. 60786086, 1997.

[85] C. Zhu, A. C. Anderson, A. Schubart et al., "The tim-3 ligand galectin-9 negatively regulates $\mathrm{T}$ helper type 1 immunity," Nature Immunology, vol. 6, no. 12, pp. 1245-1252, 2005.

[86] Q. Zhou, M. E. Munger, R. G. Veenstra et al., "Coexpression of Tim-3 and PD-1 identifies a CD $8^{+}$T-cell exhaustion phenotype in mice with disseminated acute myelogenous leukemia," Blood, vol. 117, no. 17, pp. 4501-4510, 2011.

[87] L. Golden-Mason, B. E. Palmer, N. Kassam et al., "Negative immune regulator Tim-3 is overexpressed on T cells in hepatitis $\mathrm{C}$ virus infection and its blockade rescues dysfunctional $\mathrm{CD} 4^{+}$ and CD ${ }^{+}$T cells," Journal of Virology, vol. 83, no. 18, pp. 91229130, 2009.

[88] R. H. McMahan, L. Golden-Mason, M. I. Nishimura et al., "Tim-3 expression on PD-1+ HCV-specific human CTLs is associated with viral persistence, and its blockade restores hepatocyte-directed in vitro cytotoxicity," The Journal of Clinical Investigation, vol. 120, no. 12, pp. 4546-4557, 2010.

[89] H.-T. Jin, A. C. Anderson, W. G. Tan et al., "Cooperation of Tim-3 and PD-1 in CD8 T-cell exhaustion during chronic viral infection," Proceedings of the National Academy of Sciences of the United States of America, vol. 107, no. 33, pp. 14733-14738, 2010.

[90] J. Fourcade, Z. Sun, M. Benallaoua et al., "Upregulation of Tim-3 and PD-1 expression is associated with tumor antigenspecific CD $8^{+} \mathrm{T}$ cell dysfunction in melanoma patients," Journal of Experimental Medicine, vol. 207, no. 10, pp. 2175-2186, 2010.
[91] K. Sakuishi, L. Apetoh, J. M. Sullivan, B. R. Blazar, V. K. Kuchroo, and A. C. Anderson, "Targeting tim-3 and PD-1 pathways to reverse $\mathrm{T}$ cell exhaustion and restore anti-tumor immunity," Journal of Experimental Medicine, vol. 207, no. 10, pp. 2187-2194, 2010.

[92] V. Dardalhon, A. C. Anderson, J. Karman et al., "Tim3/galectin-9 pathway: regulation of Th1 immunity through promotion of $\mathrm{CD}_{11 \mathrm{~b}}{ }^{+} \mathrm{Ly}-6 \mathrm{G}^{+}$myeloid cells," The Journal of Immunology, vol. 185, no. 3, pp. 1383-1392, 2010.

[93] D. E. Speiser, M. J. Pittet, D. Valmori et al., "In vivo expression of natural killer cell inhibitory receptors by human melanomaspecific cytolytic T lymphocytes," The Journal of Experimental Medicine, vol. 190, no. 6, pp. 775-782, 1999.

[94] E. O. Long, D. N. Burshtyn, W. P. Clark et al., "Killer cell inhibitory receptors: diversity, specificity, and function," Immunological Reviews, vol. 155, pp. 135-144, 1997.

[95] D. N. Burshtyn, A. M. Scharenberg, N. Wagtmann et al., "Recruitment of tyrosine phosphatase HCP by the killer cell inhibitory receptor," Immunity, vol. 4, no. 1, pp. 77-85, 1996.

[96] S. Lazetic, C. Chang, J. P. Houchins, L. L. Lanier, and J. H. Phillips, "Human natural killer cell receptors involved in MHC class I recognition are disulfide-linked heterodimers of CD94 and NKG2 subunits," Journal of Immunology, vol. 157, no. 11, pp. 4741-4745, 1996.

[97] R. Biassoni, C. Cantoni, M. Falco et al., "The human leukocyte antigen (HLA)-C-specific 'activatory' or 'inhibitory' natural killer cell receptors display highly homologous extracellular domains but differ in their transmembrane and intracytoplasmic portions," Journal of Experimental Medicine, vol. 183, no. 2, pp. 645-650, 1996.

[98] N. Wagtmann, R. Biassoni, C. Cantoni et al., "Molecular clones of the p58 NK cell receptor reveal immunoglobulin-related molecules with diversity in both the extra- and intracellular domains," Immunity, vol. 2, no. 5, pp. 439-449, 1995.

[99] K. C. Hsu, S. Chida, D. E. Geraghty, and B. Dupont, “The killer cell immunoglobulin-like receptor (KIR) genomic region: geneorder, haplotypes and allelic polymorphism," Immunological Reviews, vol. 190, pp. 40-52, 2002.

[100] H. J. Pegram, D. M. Andrews, M. J. Smyth, P. K. Darcy, and M. H. Kershaw, "Activating and inhibitory receptors of natural killer cells," Immunology and Cell Biology, vol. 89, no. 2, pp. 216-224, 2011.

[101] S. Kim, J. B. Sunwoo, L. Yang et al., "HLA alleles determine differences in human natural killer cell responsiveness and potency," Proceedings of the National Academy of Sciences of the United States of America, vol. 105, no. 8, pp. 3053-3058, 2008.

[102] J. Yu, J. M. Venstrom, X.-R. Liu et al., "Breaking tolerance to self, circulating natural killer cells expressing inhibitory KIR for non-self HLA exhibit effector function after T cell-depleted allogeneic hematopoietic cell transplantation," Blood, vol. 113, no. 16, pp. 3875-3884, 2009.

[103] H.-G. Ljunggren and K.-J. Malmberg, "Prospects for the use of NK cells in immunotherapy of human cancer," Nature Reviews Immunology, vol. 7, no. 5, pp. 329-339, 2007.

[104] L. Moretta and A. Moretta, "Unravelling natural killer cell function: triggering and inhibitory human NK receptors," The EMBO Journal, vol. 23, no. 2, pp. 255-259, 2004.

[105] L. Ruggeri, A. Mancusi, E. Burchielli et al., "NK cell alloreactivity and allogeneic hematopoietic stem cell transplantation," Blood Cells, Molecules, and Diseases, vol. 40, no. 1, pp. 84-90, 2008. 
[106] J. S. Miller, Y. Soignier, A. Panoskaltsis-Mortari et al., "Successful adoptive transfer and in vivo expansion of human haploidentical NK cells in patients with cancer," Blood, vol. 105, no. 8, pp. 3051-3057, 2005.

[107] H.-G. Ljunggren and K. Kärre, "In search of the 'missing self': MHC molecules and NK cell recognition," Immunology Today, vol. 11, no. 7, pp. 237-244, 1990.

[108] H.-G. Ljunggren and K. Karre, "Host resistance directed selectively against $\mathrm{H}$-2-deficient lymphoma variants. Analysis of the mechanism," The Journal of Experimental Medicine, vol. 162, no. 6, pp. 1745-1759, 1985.

[109] K. Karre, H. G. Ljunggren, G. Piontek, and R. Kiessling, "Selective rejection of $\mathrm{H}$-2-deficient lymphoma variants suggests alternative immune defence strategy," Nature, vol. 319, no. 6055, pp. 675-678, 1986.

[110] S. Giebel, F. Locatelli, T. Lamparelli et al., "Survival advantage with KIR ligand incompatibility in hematopoietic stem cell transplantation from unrelated donors," Blood, vol. 102, no. 3, pp. 814-819, 2003.

[111] D. W. Beelen, H. D. Ottinger, S. Ferencik et al., "Genotypic inhibitory killer immunoglobulin-like receptor ligand incompatibility enhances the long-term antileukemic effect of unmodified allogeneic hematopoietic stem cell transplantation in patients with myeloid leukemias," Blood, vol. 105, no. 6, pp. 2594-2600, 2005.

[112] J. S. Miller, S. Cooley, P. Parham et al., "Missing KIR ligands are associated with less relapse and increased graft-versus-host disease (GVHD) following unrelated donor allogeneic HCT," Blood, vol. 109, no. 11, pp. 5058-5061, 2007.

[113] Y. K. Tam, J. A. Martinson, K. Doligosa, and H.-G. Klingemann, "Ex vivo expansion of the highly cytotoxic human natural killer cell line NK-92 under current good manufacturing practice conditions for clinical adoptive cellular immunotherapy," Cytotherapy, vol. 5, no. 3, pp. 259-272, 2003.

[114] H.-G. Klingemann, "Natural killer cell-based immunotherapeutic strategies," Cytotherapy, vol. 7, no. 1, pp. 16-22, 2005.

[115] H. E. Kohrt, A. Thielens, A. Marabelle et al., "Anti-KIR antibody enhancement of anti-lymphoma activity of natural killer cells as monotherapy and in combination with anti-CD20 antibodies," Blood, vol. 123, no. 5, pp. 678-686, 2014.

[116] F. Romagné, P. André, P. Spee et al., "Preclinical characterization of 1-7F9, a novel human anti-KIR receptor therapeutic antibody that augments natural killer-mediated killing of tumor cells," Blood, vol. 114, no. 13, pp. 2667-2677, 2009.

[117] C. Y. Koh, B. R. Blazar, T. George et al., "Augmentation of antitumor effects by NK cell inhibitory receptor blockade in vitro and in vivo," Blood, vol. 97, no. 10, pp. 3132-3137, 2001.

[118] R. G. Goodwin, W. S. Din, T. Davis-Smith et al., "Molecular cloning of a ligand for the inducible $\mathrm{T}$ cell gene 4-1BB: a member of an emerging family of cytokines with homology to tumor necrosis factor," European Journal of Immunology, vol. 23, no. 10, pp. 2631-2641, 1993.

[119] I. Melero, W. W. Shuford, S. A. Newby et al., "Monoclonal antibodies against the 4-1BB T-cell activation molecule eradicate established tumors," Nature Medicine, vol. 3, no. 6, pp. 682-685, 1997.

[120] A. T. C. Cheuk, G. J. Mufti, and B.-A. Guinn, "Role of 4-1BB:41BB ligand in cancer immunotherapy," Cancer Gene Therapy, vol. 11, no. 3, pp. 215-226, 2004.

[121] T. H. Watts, "TNF/TNFR family members in costimulation of T cell responses," Annual Review of Immunology, vol. 23, pp. 2368, 2005.
[122] D. S. Vinay, K. Cha, and B. S. Kwon, "Dual immunoregulatory pathways of 4-1BB signaling," Journal of Molecular Medicine, vol. 84, no. 9, pp. 726-736, 2006.

[123] J. L. Cannons, Y. Choi, and T. H. Watts, "Role of TNF receptorassociated factor 2 and p38 mitogen-activated protein kinase activation during 4-1BB-dependent immune response," Journal of Immunology, vol. 165, no. 11, pp. 6193-6204, 2000.

[124] H.-W. Lee, S.-J. Park, B. K. Choi, H. H. Kim, K.-O. Nam, and B. $\mathrm{S}$. Kwon, "4-1BB promotes the survival of $\mathrm{CD}^{+} \mathrm{T}$ lymphocytes by increasing expression of Bcl- ${ }^{x} \mathrm{~L}$ and Bfl-1," The Journal of Immunology, vol. 169, no. 9, pp. 4882-4888, 2002.

[125] L. Myers, C. Takahashi, R. S. Mittler, R. J. Rossi, and A. T. Vella, "Effector CD8 T cells possess suppressor function after 4-1BB and Toll-like receptor triggering," Proceedings of the National Academy of Sciences of the United States of America, vol. 100, no. 9, pp. 5348-5353, 2003.

[126] O. Martinet, C. M. Divino, Y. Zang et al., "T cell activation with systemic agonistic antibody versus local 4-1BB ligand gene delivery combined with interleukin-12 eradicate liver metastases of breast cancer," Gene Therapy, vol. 9, no. 12, pp. 786-792, 2002.

[127] S.-H. Chen, K. B. Pham-Nguyen, O. Martinet et al., "Rejection of disseminated metastases of colon carcinoma by synergism of IL-12 gene therapy and 4-1BB costimulation," Molecular Therapy, vol. 2, no. 1, pp. 39-46, 2000.

[128] J. A. Kim, B. J. Averbook, K. Chambers et al., "Divergent effects of 4-1BB antibodies on antitumor immunity and on tumorreactive T-cell generation," Cancer Research, vol. 61, no. 5, pp. 2031-2037, 2001.

[129] S. E. Strome, B. Martin, D. Flies et al., "Enhanced therapeutic potential of adoptive immunotherapy by in vitro CD28/4-1BB costimulation of tumor-reactive T cells against a poorly immunogenic, major histocompatibility complex class I-negative A9P melanoma," Journal of Immunotherapy, vol. 23, no. 4, pp. 430-437, 2000.

[130] Q. Li, A. Carr, F. Ito, S. Teitz-Tennenbaum, and A. E. Chang, "Polarization effects of 4-1BB during CD28 costimulation in generating tumor-reactive T cells for cancer immunotherapy," Cancer Research, vol. 63, no. 10, pp. 2546-2552, 2003.

[131] I. Melero, N. Bach, K. E. Hellström, A. Aruffo, R. S. Mittler, and L. Chen, "Amplification of tumor immunity by gene transfer of the co-stimulatory 4-1BB ligand: synergy with the CD28 costimulatory pathway," European Journal of Immunology, vol. 28, no. 3, pp. 1116-1121, 1998.

[132] B.-A. Guinn, M. A. DeBenedette, T. H. Watts, and N. L. Berinstein, "4-IBBL cooperates with B7-1 and B7-2 in converting a B cell lymphoma cell line into a long-lasting antitumor vaccine," The Journal of Immunology, vol. 162, no. 8, pp. 5003-5010, 1999.

[133] S. Mogi, J. Sakurai, T. Kohsaka et al., “Tumour rejection by gene transfer of $4-1 \mathrm{BB}$ ligand into a $\mathrm{CD} 80^{+}$murine squamous cell carcinoma and the requirements of co-stimulatory molecules on tumour and host cells," Immunology, vol. 101, no. 4, pp. 541$547,2000$.

[134] J. Xiang, "Expression of Co-stimulatory 4-1BB ligand induces significant tumor regression and protective immunity," Cancer Biotherapy and Radiopharmaceuticals, vol. 14, no. 5, pp. 353-361, 1999.

[135] A. L. Gurney, S. A. Marsters, A. Huang et al., "Identification of a new member of the tumor necrosis factor family and its receptor, a human ortholog of mouse GITR," Current Biology, vol. 9, no. 4, pp. 215-218, 1999. 
[136] B. Kwon, K.-Y. Yu, J. Ni et al., "Identification of a novel activation-inducible protein of the tumor necrosis factor receptor superfamily and its ligand," The Journal of Biological Chemistry, vol. 274, no. 10, pp. 6056-6061, 1999.

[137] R. S. McHugh, M. J. Whitters, C. A. Piccirillo et al., "CD $4{ }^{+} \mathrm{CD} 25^{+}$immunoregulatory T cells: gene expression analysis reveals a functional role for the glucocorticoid-induced TNF receptor," Immunity, vol. 16, no. 2, pp. 311-323, 2002.

[138] J. Shimizu, S. Yamazaki, T. Takahashi, Y. Ishida, and S. Sakaguchi, "Stimulation of $\mathrm{CD} 25^{+} \mathrm{CD} 4^{+}$regulatory $\mathrm{T}$ cells through GITR breaks immunological self-tolerance," Nature Immunology, vol. 3, no. 2, pp. 135-142, 2002.

[139] S. Ronchetti, O. Zollo, S. Bruscoli et al., "Frontline: GITR, a member of the TNF receptor superfamily, is costimulatory to mouse T lymphocyte subpopulations," European Journal of Immunology, vol. 34, no. 3, pp. 613-622, 2004.

[140] A. P. Kohm, J. S. Williams, and S. D. Miller, "Ligation of the glucocorticoid-induced TNF receptor enhances autoreactive $\mathrm{CD}^{+} \mathrm{T}$ cell activation and experimental autoimmune encephalomyelitis," The Journal of Immunology, vol. 172, no. 8, pp. 4686-4690, 2004.

[141] F. Kanamaru, P. Youngnak, M. Hashiguchi et al., "Costimulation via glucocorticoid-induced TNF receptor in both conventional and $\mathrm{CD}_{2} 5^{+}$regulatory $\mathrm{CD} 4^{+} \mathrm{T}$ cells," Journal of Immunology, vol. 172, no. 12, pp. 7306-7314, 2004.

[142] G. Nocentini and C. Riccardi, "GITR: a multifaceted regulator of immunity belonging to the tumor necrosis factor receptor superfamily," European Journal of Immunology, vol. 35, no. 4, pp. 1016-1022, 2005.

[143] B. J. Kim, Z. Li, R. N. Fariss et al., "Constitutive and cytokineinduced GITR ligand expression on human retinal pigment epithelium and photoreceptors," Investigative Ophthalmology and Visual Science, vol. 45, no. 9, pp. 3170-3176, 2004.

[144] E. M. Shevach and G. L. Stephens, "The GITR-GITRL interaction: co-stimulation or contrasuppression of regulatory activity?" Nature Reviews Immunology, vol. 6, no. 8, pp. 613-618, 2006.

[145] D. A. Schaer, "GITR pathway activation abrogates tumor immune suppression through loss of regulatory $\mathrm{T}$ cell lineage stability," Cancer Immunology Research, vol. 1, no. 5, pp. 320-331, 2013.

[146] R.-R. Ji, S. D. Chasalow, L. Wang et al., "An immune-active tumor microenvironment favors clinical response to ipilimumab," Cancer Immunology, Immunotherapy, vol. 61, no. 7, pp. 1019-1031, 2012.

[147] S. Cuzzocrea, E. Ayroldi, R. Di Paola et al., "Role of glucocorticoid-induced TNF receptor family gene (GITR) in collageninduced arthritis," The FASEB Journal, vol. 19, no. 10, pp. 12531265, 2005.

[148] M. Patel, D. Xu, P. Kewin et al., "Glucocorticoid-induced TNFR family-related protein (GITR) activation exacerbates murine asthma and collagen-induced arthritis," European Journal of Immunology, vol. 35, no. 12, pp. 3581-3590, 2005.

[149] M. Takata, T. Nakagomi, S. Kashiwamura et al., "Glucocorticoid-induced TNF receptor-triggered $\mathrm{T}$ cells are key modulators for survival/death of neural stem/progenitor cells induced by ischemic stroke," Cell Death and Differentiation, vol. 19, no. 5, pp. 756-767, 2012.

[150] A. D. Cohen, D. A. Schaer, C. Liu et al., "Agonist anti-GITR monoclonal antibody induces melanoma tumor immunity in mice by altering regulatory $\mathrm{T}$ cell stability and intra-tumor accumulation," PLoS ONE, vol. 5, no. 5, Article ID e10436, 2010.
[151] G. L. Stephens, R. S. McHugh, M. J. Whitters et al., "Engagement of glucocorticoid-induced TNFR family-related receptor on effector $\mathrm{T}$ cells by its ligand mediates resistance to suppression by $\mathrm{CD} 4{ }^{+} \mathrm{CD} 25^{+}$T cells," The Journal of Immunology, vol. 173, no. 8, pp. 5008-5020, 2004.

[152] M. J. Turk, J. A. Guevara-Patiño, G. A. Rizzuto, M. E. Engelhorn, and A. N. Houghton, "Concomitant tumor immunity to a poorly immunogenic melanoma is prevented by regulatory $\mathrm{T}$ cells," The Journal of Experimental Medicine, vol. 200, no. 6, pp. 771-782, 2004.

[153] D. A. Schaer, J. T. Murphy, and J. D. Wolchok, "Modulation of GITR for cancer immunotherapy," Current Opinion in Immunology, vol. 24, no. 2, pp. 217-224, 2012.

[154] D.-M. Kuang, Q. Zhao, C. Peng et al., "Activated monocytes in peritumoral stroma of hepatocellular carcinoma foster immune privilege and disease progression through PD-L1," The Journal of Experimental Medicine, vol. 206, no. 6, pp. 1327-1337, 2009.

[155] J. Krempski, L. Karyampudi, M. D. Behrens et al., "Tumorinfiltrating programmed death receptor- $1^{+}$dendritic cells mediate immune suppression in ovarian cancer," The Journal of Immunology, vol. 186, no. 12, pp. 6905-6913, 2011.

[156] M. J. Gough and M. R. Crittenden, "Combination approaches to immunotherapy: the radiotherapy example," Immunotherapy, vol. 1, no. 6, pp. 1025-1037, 2009.

[157] E. M. Rosen, S. Fan, S. Rockwell, and I. D. Goldberg, "The molecular and cellular basis of radiosensitivity: implications for understanding how normal tissues and tumors respond to therapeutic radiation," Cancer Investigation, vol. 17, no. 1, pp. 5672, 1999.

[158] S. A. Grossman, X. Ye, G. Lesser et al., "Immunosuppression in patients with high-grade gliomas treated with radiation and temozolomide," Clinical Cancer Research, vol. 17, no. 16, pp. 5473-5480, 2011.

[159] W. H. McBride, C.-S. Chiang, J. L. Olson et al., "A sense of danger from radiation," Radiation Research, vol. 162, no. 1, pp. $1-19,2004$.

[160] S. Demaria and S. C. Formenti, "Sensors of ionizing radiation effects on the immunological microenvironment of cancer," International Journal of Radiation Biology, vol. 83, no. 11-12, pp. 819-825, 2007.

[161] M. L. Albert, B. Sauter, and N. Bhardwaj, "Dendritic cells acquire antigen from apoptotic cells and induce class Irestricted CTLS," Nature, vol. 392, no. 6671, pp. 86-89, 1998.

[162] E. J. Friedman, "Immune modulation by ionizing radiation and its implications for cancer immunotherapy," Current Pharmaceutical Design, vol. 8, no. 19, pp. 1765-1780, 2002.

[163] B. Sauter, M. L. Albert, L. Francisco, M. Larsson, S. Somersan, and N. Bhardwaj, "Consequences of cell death: exposure to necrotic tumor cells, but not primary tissue cells or apoptotic cells, induces the maturation of immunostimulatory dendritic cells," Journal of Experimental Medicine, vol. 191, no. 3, pp. 423433, 2000.

[164] D. Zagzag, K. Salnikow, L. Chiriboga et al., "Downregulation of major histocompatibility complex antigens in invading glioma cells: stealth invasion of the brain," Laboratory Investigation, vol. 85, no. 3, pp. 328-341, 2005.

[165] H. Wiendl, M. Mitsdoerffer, V. Hofmeister et al., "A functional role of HLA-G expression in human gliomas: an alternative strategy of immune escape," The Journal of Immunology, vol. 168, no. 9, pp. 4772-4780, 2002.

[166] E. W. Newcomb, S. Demaria, Y. Lukyanov et al., "The combination of ionizing radiation and peripheral vaccination produces 
long-term survival of mice bearing established invasive GL261 gliomas," Clinical Cancer Research, vol. 12, no. 15, pp. 4730-4737, 2006.

[167] S. Demaria, N. Kawashima, A. M. Yang et al., "Immunemediated inhibition of metastases after treatment with local radiation and CTLA- 4 blockade in a mouse model of breast cancer," Clinical Cancer Research, vol. 11, no. 2, part 1, pp. 728734, 2005.

[168] M. Z. Dewan, A. E. Galloway, N. Kawashima et al., "Fractionated but not single-dose radiotherapy induces an immunemediated abscopal effect when combined with anti-CTLA-4 antibody," Clinical Cancer Research, vol. 15, no. 17, pp. 53795388, 2009.

[169] A. W. Silk, M. F. Bassetti, B. T. West, C. I. Tsien, and C. D. Lao, "Ipilimumab and radiation therapy for melanoma brain metastases," Cancer Medicine, vol. 2, no. 6, pp. 899-906, 2013.

[170] A. S. Darefsky, J. T. King Jr., and R. Dubrow, "Adult glioblastoma multiforme survival in the temozolomide era: a populationbased analysis of surveillance, epidemiology, and end results registries," Cancer, vol. 118, no. 8, pp. 2163-2172, 2012.

[171] R. Stupp, M. E. Hegi, T. Gorlia et al., "Cilengitide combined with standard treatment for patients with newly diagnosed glioblastoma with methylated MGMT promoter (CENTRIC EORTC 26071-22072 study): a multicentre, randomised, openlabel, phase 3 trial," The Lancet Oncology, vol. 15, no. 10, pp. 11001108, 2014.

[172] C. L. Mackall, T. A. Fleisher, M. R. Brown et al., "Lymphocyte depletion during treatment with intensive chemotherapy for cancer," Blood, vol. 84, no. 7, pp. 2221-2228, 1994.

[173] Y. B. Su, S. Sohn, S. E. Krown et al., "Selective CD4 ${ }^{+}$lymphopenia in melanoma patients treated with temozolomide: a toxicity with therapeutic implications," Journal of Clinical Oncology, vol. 22, no. 4, pp. 610-616, 2004.

[174] J. L. Frazier, J. E. Han, M. Lim, and A. Olivi, "Immunotherapy combined with chemotherapy in the treatment of tumors," Neurosurgery Clinics of North America, vol. 21, no. 1, pp. 187-194, 2010.

[175] S. Brem, B. Tyler, K. Li et al., "Local delivery of temozolomide by biodegradable polymers is superior to oral administration in a rodent glioma model," Cancer Chemotherapy and Pharmacology, vol. 60, no. 5, pp. 643-650, 2007.

[176] S. Fritzell, E. Sandén, S. Eberstål, E. Visse, A. Darabi, and P. Siesjö, "Intratumoral temozolomide synergizes with immunotherapy in a T cell-dependent fashion," Cancer Immunology, Immunotherapy, vol. 62, no. 9, pp. 1463-1474, 2013.

[177] C. Banissi, F. Ghiringhelli, L. Chen, and A. F. Carpentier, "Treg depletion with a low-dose metronomic temozolomide regimen in a rat glioma model," Cancer Immunology, Immunotherapy, vol. 58, no. 10, pp. 1627-1634, 2009. 


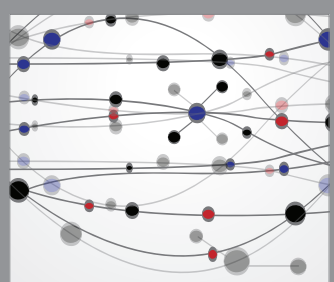

The Scientific World Journal
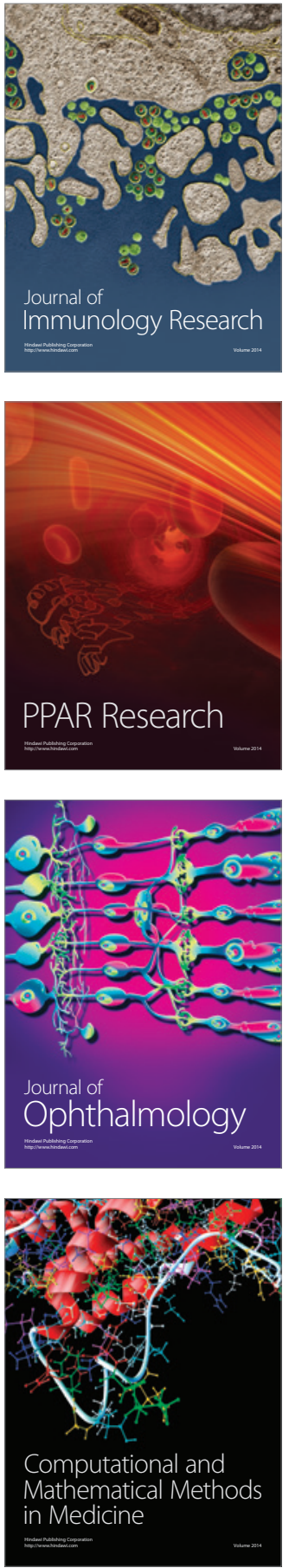

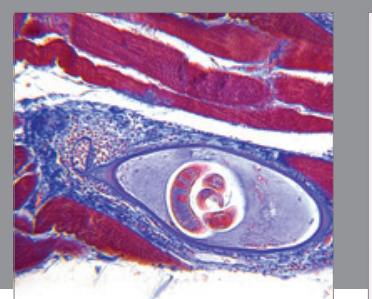

Gastroenterology Research and Practice

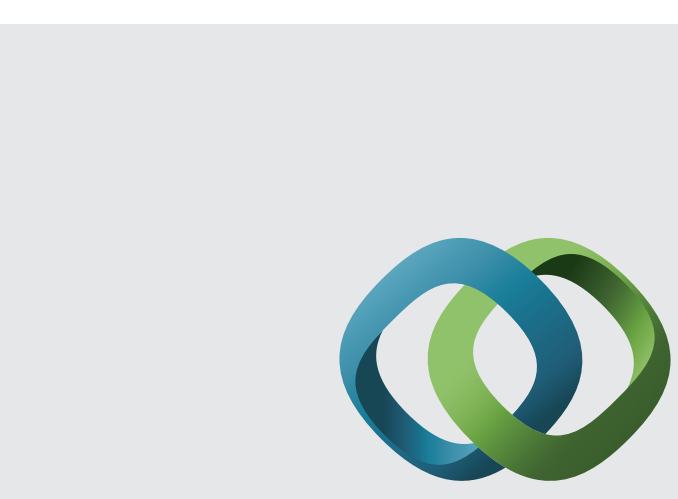

\section{Hindawi}

Submit your manuscripts at

http://www.hindawi.com
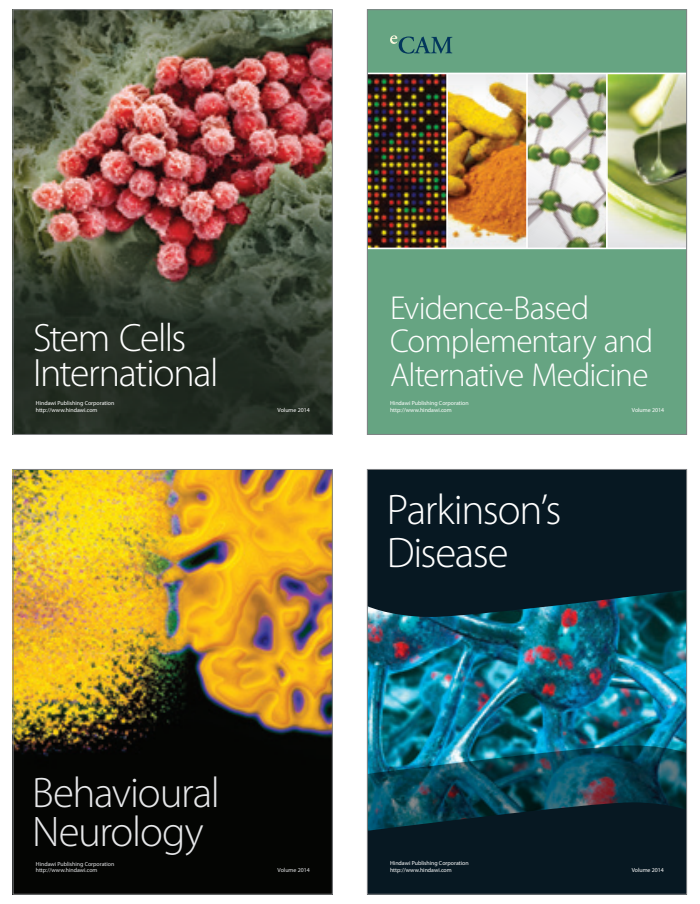
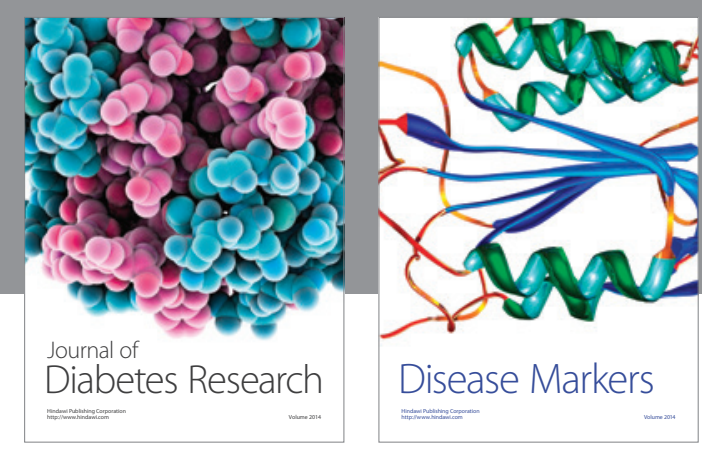

Disease Markers
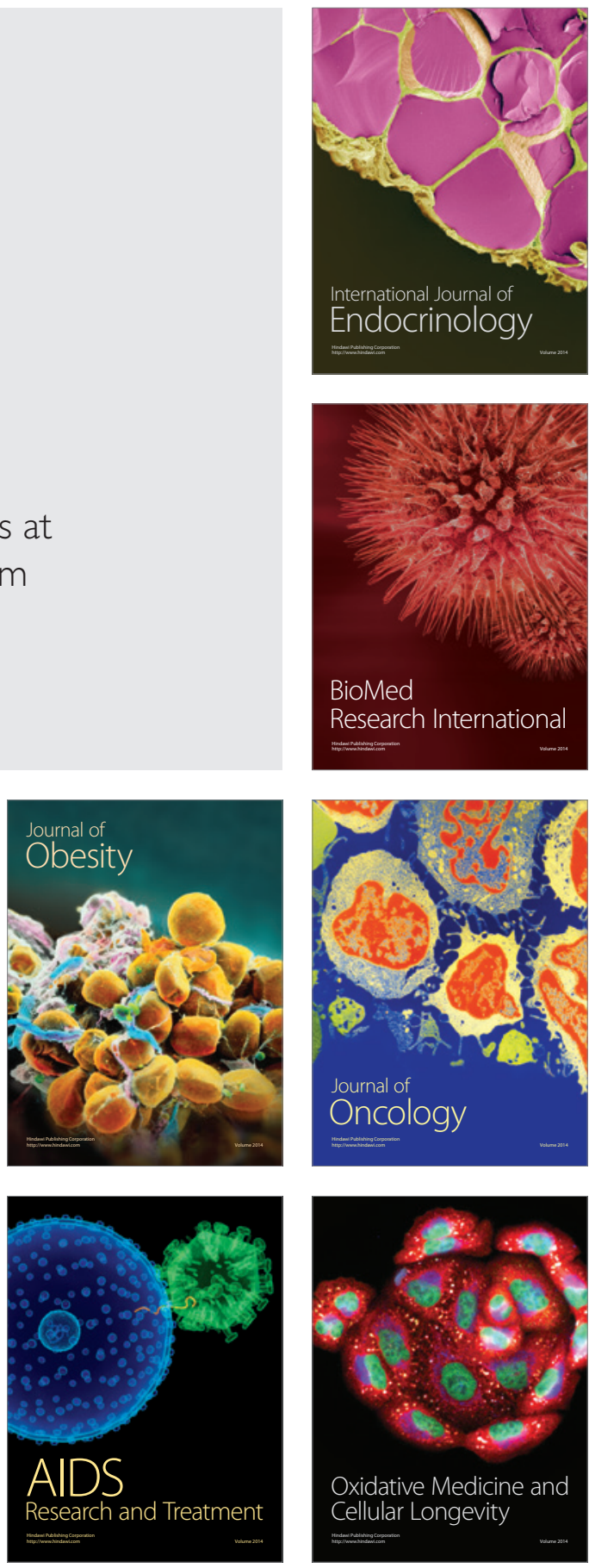